Wright State University

CORE Scholar

\title{
Work-Nonwork Goal Conflict: A Self-Regulatory Expansion of Work Life Conflict
}

John Michael McKee

Wright State University

Follow this and additional works at: https://corescholar.libraries.wright.edu/etd_all

Part of the Industrial and Organizational Psychology Commons

\section{Repository Citation}

McKee, John Michael, "Work-Nonwork Goal Conflict: A Self-Regulatory Expansion of Work Life Conflict" (2007). Browse all Theses and Dissertations. 199.

https://corescholar.libraries.wright.edu/etd_all/199

This Dissertation is brought to you for free and open access by the Theses and Dissertations at CORE Scholar. It has been accepted for inclusion in Browse all Theses and Dissertations by an authorized administrator of CORE Scholar. For more information, please contact library-corescholar@wright.edu. 


\section{WORK-NONWORK GOAL CONFLICT: A SELF-REGULATORY EXPANSION OF WORK LIFE CONFLICT}

A dissertation submitted in partial fulfillment of the requirements for the degree of

Doctor of Philosophy

By

JOHN MICHAEL MCKEE

B.A., The Ohio State University, 2001

M.Ed. Washington State University, 2003

M.S. Wright State University, 2006

2007

Wright State University 


\section{WRIGHT STATE UNIVERSITY \\ SCHOOL OF GRADUATE STUDIES}

September 6, 2007

\section{HEREBY RECOMMEND THAT THE DISSERTATION PREPARED UNDER} MY SUPERVISION BY John Michael McKee ENTITLED Work-Nonwork Goal Conflict: A Self-Regulatory Expansion of Work-Life Conflict BE ACCEPTED IN PARTIAL FULFILLMENT OF THE REQUIREMENTS FOR THE DEGREE OF Doctor of Philosophy.

Jean M. Edwards, Ph.D.

Dissertation Director

John M. Flach, Ph.D.

Graduate Program Director

Joseph F. Thomas, Jr., Ph.D.

Dean, School of Graduate Studies

Committee on

Final Examination

Jean M. Edwards, Ph.D.

John R. Rudisill, Ph.D.

Corey E. Miller, Ph.D.

Nathan A. Bowling, Ph.D. 


\begin{abstract}
McKee, John M. Department of Psychology, Wright State University, 2007. Worknonwork Goal Conflict: A Self-Regulatory Expansion of Work-Life Conflict.
\end{abstract}

Current conceptualizations of work-life conflict (WLC) fail to account for additional life domains beyond that already measured for by traditional work-family conflict (WFC) measures. When conceptualized from a self-regulatory perspective, WFC can be thought of as a person's work goals conflicting with his or her family goals. This goal-based conceptualization of WLC was used within the current study in order to explore the relationship between work-nonwork goal conflict and worker well-being. Participants were guided through an on-line personal project analysis, in which they elicited goals within work and nonwork domains and then provided ratings of conflict between all work and nonwork goals. Results of this research support the utility of examining life domains, such as social life, academics, and selfcare when attempting to understand the relationship between intergoal conflict and employee well-being. 


\section{TABLE OF CONTENTS}

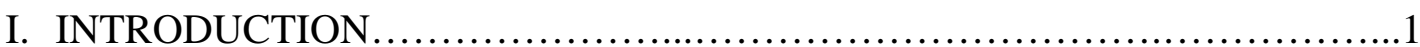

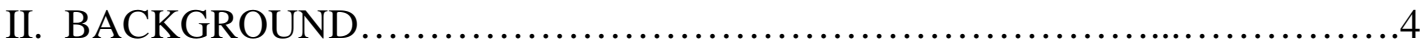

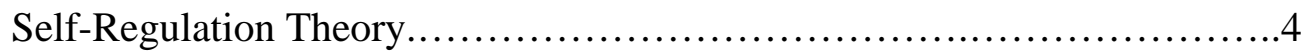

Feedback loops...................................................

Coping within a self-regulation framework...........................6

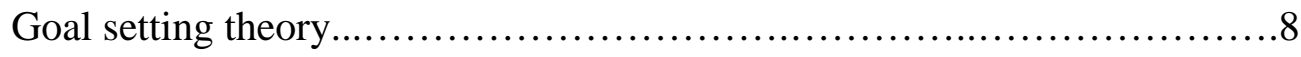

Personal project analysis.............................................12

Outcomes associated with personal projects............................17

Goal Conflict.......................................................

Work Family Conflict.............................................27

Work Academic Conflict.............................................

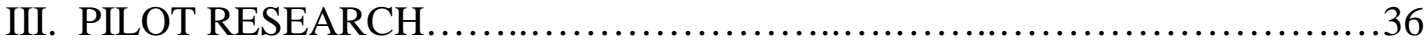

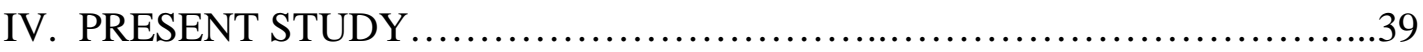

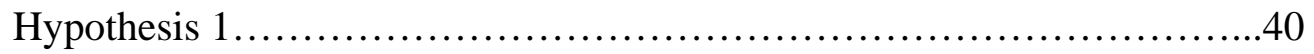

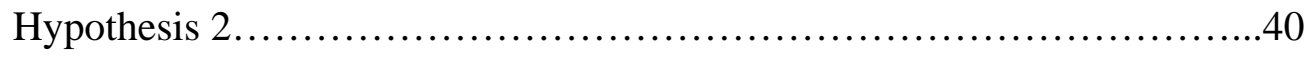

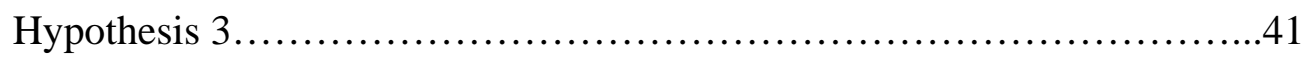

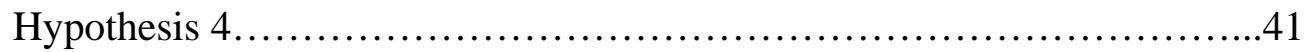

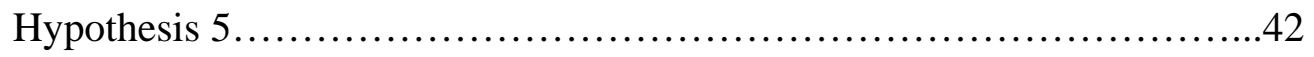

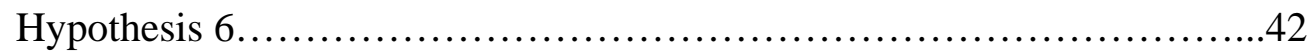




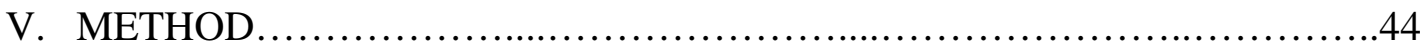

Participants and procedures.........................................44

Measures.................................................................. 45

Work-nonwork and nonwork-work conflict.........................45

Work-life conflict..............................................46

Goal disengagement and reengagement coping.......................46

Self-report physical well-being measure $\ldots \ldots \ldots \ldots \ldots \ldots \ldots \ldots \ldots \ldots \ldots . .47$

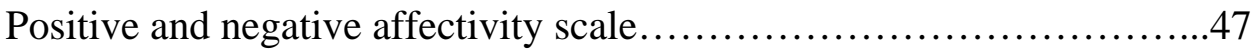

Job satisfaction................................................... 48

Turnover intentions................................................ 48

General demographics.........................................48

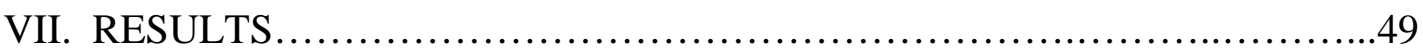

Descriptive Statistics...............................................49

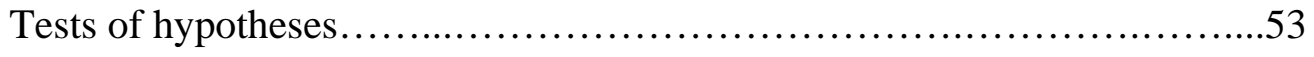

Checking assumptions.............................................53

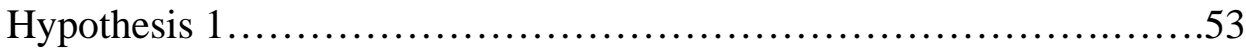

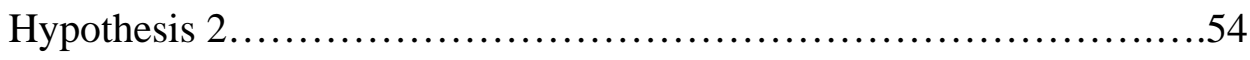

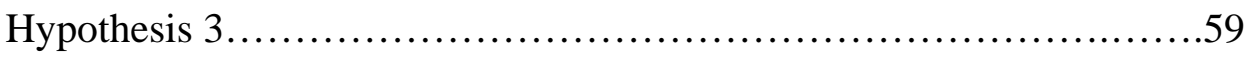

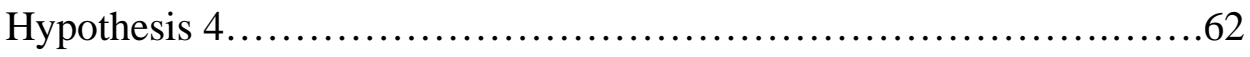

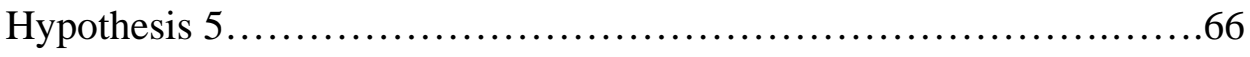

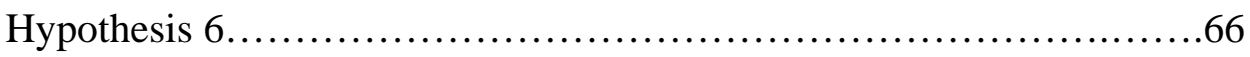

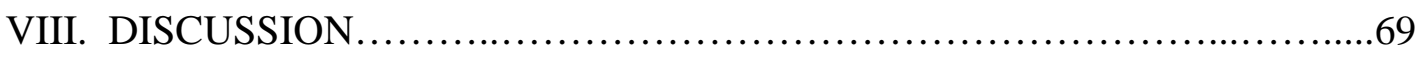

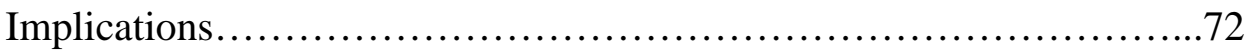


Limitations..........................................................

Future Research................................................76

IX. CONCLUSION....................................................... 78

APPENDICES

A. Personal project survey.........................................83

B. Work family and family work scale..................................87

C. Work school and school work conflict scale..............................88

D. Goal disengagement and goal reengagement scale.....................89

E. Physical symptoms inventory...................................... 90

F. Positive and negative affectivity scale $\ldots \ldots \ldots \ldots \ldots \ldots \ldots \ldots \ldots \ldots \ldots \ldots \ldots$. $\ldots \ldots \ldots \ldots$

G. Job satisfaction scale............................................... 92

H. Turnover intentions...........................................93

I. General Demographics.........................................94

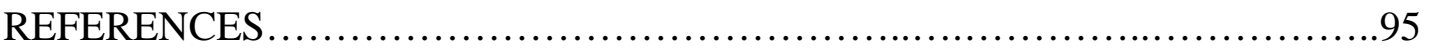




\section{LIST OF FIGURES}

\section{Figure}

1. Interaction of reengagement coping and $\mathrm{W}-\mathrm{GNW}$ predicting job satisfaction.................................................... 80

2. Interaction of disengagement coping and GNW-W predicting negative affect.................................................... 81

3. Interaction of reengagement coping and AWC predicting job

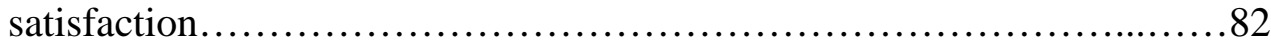




\section{LIST OF TABLES}

Table

1. Means, Standard Deviations and Intercorrelations of Predictor and Outcome Variables $(\mathrm{N}=229)$...

2. Hierarchical Regression of Physical Symptoms (PSI), Positive Affect, Negative Affect, Job Satisfaction, and Turnover Intentions on Specific Work-Nonwork Conflicts

3. Hierarchical Regression of Physical Symptoms (PSI), Positive Affect, Negative Affect, Job Satisfaction, and Turnover Intentions on Specific Nonwork-Work Conflicts.

4. Hierarchical Regression of Physical Symptoms (PSI) on Specific Work-Nonwork Conflicts, Having Controlled for a Pre-existing Measure of Work-Family Conflict

5. Hierarchical Regression of Job Satisfaction on Reengagement Coping Interacting with Work Conflicting with Global Nonwork Conflicts, Having Controlled for Work Conflicting with Global Nonwork and Reengagement Coping .63

6. Hierarchical Regression of Negative Affect on Disengagement Coping Interacting with Global Nonwork Conflicting with Work, Having Controlled for Global Nonwork Conflicting with Work and Reengagement Coping

7. Hierarchical Regression of Job Satisfaction on Reengagement Coping Interacting with Academic-Work Conflict, Having Controlled for Academic-Work Conflict and Reengagement Coping 


\section{ACKNOWLEGEMENT}

I would like to thank all of the people who supported me through graduate school and the completion of my dissertation. In particular, I would like to thank my mother and father for their encouragement and assistance. I also wish to express appreciation for the guidance provided by my dissertation committee members, Professor Corey E. Miller, Professor Nathan A. Bowling, Professor John R. Rudisill, and Professor Jean M. Edwards. As the chair of my dissertation committee, faculty advisor, and mentor, I am forever thankful for the influence Dr. Edwards has had on my academic training and professional development. Last but not least, I am thankful for the support and inspiration provided to me by my loving wife Wendy. 


\section{DEDICATION}

This is dedicated to my best friend Wendy. 


\section{Introduction}

Work family conflict (WFC) and Family work conflict (FWC) are widely acknowledged as being major occupational stressors and are linked to several negative interpersonal, psychological, and organizational outcomes (Anderson, Coffey, \& Byerly, 2002; Grzywacz, 2000; Frone, Russell, \& Cooper, 1997; Perrewé, Hochwarter, \& Kiewitz, 1999). When conceptualized from a selfregulatory perspective, WFC can be thought of as a person's work goals conflicting with his or her family goals. Likewise, FWC can be compared to family goals conflicting with work goals (Edwards, 1998; Bellavia \& Frone, 2005). Furthermore, when viewed from this perspective, other work-nonwork goal conflicts (other than WFC and FWC) are likely to exist beyond family goals. For example, work-social life, work-academics, and work-self-care goal conflicts may contribute to individual stress levels and negatively impact both the worker and the workplace. Although WFC and FWC have been extensively studied, research into goal-based conceptualizations of WFC/FWC is lacking. Similarly, the multitudes of other potential work-nonwork goal conflicts have yet to be examined.

Goals have been, and continue to be, an important psychological construct within the workplace. Frequently, the study of occupational goals has been restricted to employee outcomes associated with difficulty of supervisor assigned goals (Locke \& Latham, 1990). Also common, is the consideration of goals from 
the perspective of the individual employee. In these instances (Button, Mathieu, \& Zajac, 1996; Murphy \& Cleveland, 1995; McKee et al., 2006), reporting of individually held goals is accomplished through structured interview techniques or survey methods and is also restricted to a limited number of possible goal topics (e.g., performance/mastery goals, desired fairness during performance evaluation, or preferred level of workload). As such, the work goal literature has not effectively explored the numerous potential goal conflict relationships in existence. Self-regulation theory (Carver \& Scheier, 1999) is a useful perspective from which one can conceptualize previous goal research as well as attempt to understand the influence of multiple goals on the individual. Self-regulation theory contends that all individually held goals are arranged hierarchically and that each individual's hierarchical arrangement of goals is unique. When considered from this self-regulation perspective, previous research into work goals appears lacking due to the limited number of possible goal categories studied. A more thorough analysis of individually held goals becomes possible through Personal Project Analysis (PPA) as outlined by Little (1983). Common to all studies of personal projects is the participant guided elicitation of personally relevant goals. As a result, this participant focused approach to understanding goals across a wide variety of domains is an important improvement upon the vast majority of occupational research into goals. Furthermore, due to the broad sampling of participant goals present within PPA, a means is provided by which multiple worknonwork goal conflicts can be examined. 
The PPA has proven to be useful in gaining greater insight into the selfregulatory mechanisms (Carver \& Scheier, 1999) behind several physical and psychological outcomes. Although primarily studied in non-occupational settings (e.g., Brunstein, 1993; McGregor \& Little, 1998; Salmela-Aro \& Nurmi, 1997), the limited research utilizing the PPA within work settings has shown great promise (e.g., Christiansen, Backman, Little \& Nguyen, 1999; Maier \& Brunstein, 2001; Nurmi \& Salmela-Aro, 2002). These first steps to explore the possible applications of the PPA approach within an organizational context have been limited to outcomes such as job satisfaction, organizational commitment, and employee wellbeing. However, these few studies examining employee personal projects have neglected to examine the effect of conflicting personal projects such as WFC or other work-nonwork conflicts.

Continuing to explore personal projects in relationship to work goal conflict, as well as in relationship to outcomes relevant to both individuals and organizations may provide an important insight into employee goals and expand our understanding of work life conflict (WLC). As such, the pilot work and subsequent study outlined in this document attempt to examine the association between conflicting personal projects and occupationally relevant measures among an employed undergraduate population. 


\section{Background}

\section{Self-Regulation Theory}

The Carver and Scheier (1999) model of self-regulation is based on control theory (Campion \& Lord, 1982; Powers, 1973) and emphasizes the importance of feedback loops to achieve discrepancy reduction. Additionally, the Carver and Scheier model draws from the psychologically based conceptualization of stress proposed by Lazarus and Folkman (1984). As such, Carver and Scheier contend that affect is the result of an appraisal processes comparing one's desired progress toward a goal state and the actual progress experienced by the individual. Perceived discrepancies between environmental inputs and internal standards of goal progress result in negative affect and initiate coping, which is the regulation or maintenance of goal directed effort. According to the Carver and Scheier selfregulatory perspective, increased negative affect is experienced when impediments to progress exist in relationship toward desired "do" or "be" goals or away from anti-goals.

From a self-regulation perspective, individually held goals are arranged within goal hierarchies comprised of implicit and explicit superordinate be goals (e.g., 'I want to be a good employee' or 'I want to be a good father') supported by subordinate do goals (e.g., 'I need to do the task my boss has given me' or 'I need to pick up the kids from soccer practice') at increasingly lower levels of abstraction. 
Be goals can be further divided into lower level principles (such as 'be a good employee') and higher order systems concepts, which are goals that guide all behavior and embody the ideal self. An example of this might consist of a system concept of 'be respected' supported by principles of 'be a good employee,' 'be a good citizen,' and 'be a good caregiver.'

Goal importance is determined by each goal's location within a hierarchy of goals as well as the degree to which each goal contributes to the attainment of one or more superordinate goals. The formation of goal hierarchies is an individually determined process and as such, a subordinate do goal 'do my homework' that contributes to multiple higher level be goals 'be successful,' 'be educated,' etc., would be seen as being very important, whereas a lower order goal 'do the crossword puzzle' that contributes to only one higher level goal 'be relaxed' is seen as less important.

Feedback Loops. Self-regulation theory proposes that internalized standards act as reference criteria, within positive and negative feedback loops. The purpose of these feedback loops constitutes either discrepancy reduction or discrepancy enlargement. Each goal's feedback loop serves to enable individuals to progress toward specific desired goals (positive feedback loop) or away from specific undesired "anti" goals (negative feedback loop) (Carver \& Scheier, 1999). An example of an anti-goal would be an individual actively avoiding any activity that would contribute to his or her being fired. The state of being fired would be considered the anti-goal, from which the individual is actively trying to move away. 
Closely related to individual positive and negative feedback loops, selfregulatory affective feedback loops assess the degree to which impediments to progress exist in relationship toward desired do or be goals or away from anti-goals. In cases where a less than desirable rate of goal progress is being made, negative affect results. Similarly, positive affect is experienced when satisfactory progress is being made toward one's goals or away from one's anti-goal. To continue the example of an individual with the anti-goal of being fired, perceived movement toward the anti-goal of being fired (increasing one's risk of being fired) would increase the individual's level of negative affect. As such, the purpose of the selfregulatory positive, negative, and affective feedback loops is discrepancy reduction, whether between an ideal state and an actual state or the rate at which one is making progress toward his or her ideal goal state. Individual appraisals of discrepancies between environmental inputs and standards initiate regulation or maintenance of effort. This regulation and maintenance of effort resulting from perceived discrepancies is conceptualized as coping from a self-regulation perspective.

Coping within a self-regulation framework. When individuals experience discrepancies between a desired state (goal state) and their current state, or when individuals perceive they are not making acceptable progress toward their goals, coping occurs (Carver \& Scheier, 1999). Possible self-regulatory coping strategies include: giving up, goal disengagement, goal reengagement, and scaling back of goals (limited disengagement from original goal). Disengagement from a particular do or be goal does not necessarily imply that higher order goals will not be attained. Multiple routes to goal attainment are hypothesized to exist within each individual's 
goal hierarchy. As such, during situations where disengagement from a lower goal is necessary, alternate lower goals may serve as a path to achieving goals situated higher within an individual's goal hierarchy. For example, an employee may disengage from the lower level goal of arriving early to work and engage in the alternative goal of staying late at work in order to fulfill the higher order goal of being a good employee. This identification of, and engagement in, alternative goals is referred to as goal reengagement and allows for individuals to maintain goal progress and experience positive affect.

Wrosch, Scheier, Miller, Schulz, and Carver's (2003) findings in three separate studies showed that positive outcomes for individual well-being resulted for people who were more likely to disengage completely from unattainable goals. Furthermore, levels of well-being in excess of the disengage group resulted for those individuals that were more likely to reengage in other achievable goals prior to or following goal disengagement. Although individuals employing more reengage than disengage coping strategy tend to have higher levels of subjective well-being, Wrosch and colleagues suggest that the process of finding new goals to pursue can be, in and of itself, stressful. This suggests that the availability of multiple alternative goals can facilitate the reengage process and ultimately be associated with greater levels of well-being.

Currently, McKee et al. $(2006 ; 2007)$ is the only effort to examine the value of disengagement and reengagement coping strategies within the workplace. Although cross-sectional in nature, this research shows promise for disengagement and reengagement coping strategies as occupationally relevant constructs. McKee 
and colleagues (2006) found disengagement coping to significantly predict workplace strains such as reduced sense of personal accomplishment (burnout). Similarly McKee and group (2007), found that reengagement coping predicts lower levels of workplace burnout and boredom. It is possible that through the use of a less constrained work population and a more accurate measure of goals, disengagement and reengagement coping strategies will further predict other occupationally relevant constructs.

\section{Goal-Setting Theory}

A similar theory to that of self-regulation is the goal-setting theory proposed by Locke and Latham (1990). Focusing primarily on task performance goals and subsequent levels of performance, this theoretical perspective does not focus on specific actions or intentions of an individual (Locke \& Latham, 2002).

Extensively studied within the field of applied psychology, goal-setting theory's primary findings focus on the positive linear relationship between goal difficulty and performance within the work context. Another major finding of the theory of goal-setting is that individual goal commitment moderates the relationship between goal difficulty and performance (Klein, Wesson, Hollenbeck, \& Alge, 1999; Locke, 1968). An individual's likelihood of becoming committed to a set goal (choosing to pursue a set goal) relies upon perceptions of likelihood of goal attainability, desirability of the set goal, perceptions of past performance on similar goals, and individual levels of self-efficacy (Locke \& Latham, 2002).

Within the goal setting framework, three motivational mechanisms come into play once an individual is committed to a goal: effort, persistence and direction 
(Locke \& Latham, 1990). Effort is increased by an individual in order to achieve a more difficult goal. Persistence (i.e., spending longer amounts of time) is required for a more difficult goal to be achieved and the direction of attention and effort toward goal relevant behaviors is necessary. From a self-regulation framework, the constructs of effort, persistence, and direction are all encompassed with the discrepancy reduction feedback loop, so that once a discrepancy between ideal and actual goal state is perceived, increased effort is applied in the direction of desired goal progress and persistence of this effort (coping) is maintained until the goal discrepancy is no longer perceived.

Despite the enormous overlap between self-regulation theory and goalsetting theory, Locke and Latham (2002) state that self-regulation theory, as proposed by Carver and Scheier, is “....in effect a mechanistic version of Hull's drive reduction theory, which was abandoned decades ago" (p. 708). Locke and Latham underscore this statement by arguing that the discrepancy reduction feedback loops present within the self-regulation framework lead to a state of motionlessness or rest, due to a goal's discrepancy level being reduced to zero once a goal has been accomplished. Furthermore, Locke and Latham contend that selfregulation theory does not allow for "feed-forward" but instead only allows feedback. By an absence of feed-forward, Lock and Latham are suggesting that self-regulation theory does not allow for the setting of additional more difficult goals once a particular goal has been accomplished within a self-regulation framework. Ultimately, Locke and Latham argue that this lack of self-created goals 
reduces the individual to a machine like state, wherein the machine/individual awaits further commands from its builders.

Although Carver and Scheier's (1999) description of self-regulation theory focuses on the effect of perceived progress toward goal states and individual striving to reduce discrepancies within their feedback loops, the theory does not explicitly expound upon the setting of work related goals. Edwards' (1992) cybernetic theory of stress, coping and well-being (an application of Carver and Scheier's model of self-regulation theory as it pertains to the workplace) does, however, discuss setting of goals. Furthermore, Edwards (1998) responds to Locke's (1994) previously made criticisms pertaining to self-regulation theory. As the most recent review of goal setting theory supplied by Locke and Latham (2002) does not acknowledge nor refute the counterarguments made in favor of selfregulation theory (Edwards, 1998), and instead reissues the old 1994 criticisms again, a brief review of Edwards' support of self-regulation is supplied at this point.

Edwards (1998) addressed the three common criticisms against selfregulation theory. Specifically, the first criticism contends that self-regulation theory describes the behaviors of machines and is therefore not able to fully explain human behavior. Furthermore, self-regulation theory barrows from mechanistic theories and ultimately does not have anything unique to offer of its own. The second common criticism made is that self-regulation theory focuses solely on discrepancy reduction and that discrepancy creation is not accounted for. The final criticism refuted by Edwards states that self-regulation theory does not account for behavior arising from individual forethought regarding future goals or goal 
discrepancies. As can be seen, these issues are point for point the criticisms made by Locke and Latham (2002).

Responding to the first criticism, Edwards (1998) suggests that selfregulation theory has elaborated upon the basic mechanistic principles to arrive at a more complex theory of human cognition and behavior. Furthermore, although early mechanistic versions were created in order to control automated devices such as servomechanisms, these control systems were created to mimic human behavior as it naturally occurs and therefore are relevant to a human oriented theory. In response to the second criticism, Edwards contends that discrepancy creation is an essential part of self-regulation theory and that discrepancies are created during the selection of environmental standards against which one's goal progress is compared. Additionally, goals are arranged hierarchically within the self-regulation framework and higher order goals implicitly set standards for lower level goals. The third common criticism of self-regulation theory was addressed by Edwards by reviewing the role of higher order goals within a self-regulation framework. Specifically, higher order goals are commonly long-term goals such as 'live a long happy life' and guide lower order goals not only in terms of behavior but also in the level of standard against which goal progress will be compared. Moreover, individual focus of attention on particular goals at lower levels of one's goal hierarchy is shifted in order to maintain acceptable progress toward higher order goals and therefore "...forethought is integral to the selection and setting of lower level standards to achieve higher level goals" (pg. 126). 
Ultimately, goal-setting theory is neither at odds with, nor separate from, self-regulation theory. Instead, the theory of goal-setting fits within self-regulation theory and primarily focuses on performance related goals, which are comparable to the mid-level "do goals" within the self-regulation framework. As a result, all further discussion of goals within this paper will be referred to in terms of selfregulatory processes.

\section{Personal Project Analysis}

The study of personal projects allows researchers to accurately explore the interrelatedness of several different goals within an individual's goal hierarchy. Little (1983) describes a personal project as being “.... a set of interrelated acts extending over time, which is intended to maintain or attain a state of affairs foreseen by the individual” (p. 276). As such, personal projects fit well within the self-regulatory framework proposed by Carver and Scheier (1999) and allow for the examination of goal conflicts proposed by Edwards (1998). Due to their conceptual overlap, the terms personal project and goal will be used interchangeably throughout the remainder of this paper.

Little and Gee (2007) emphasize that the PPA approach to understanding individual goals is a modular approach and researchers are encouraged to select or modify those modules of the PPA that best meet their needs (see Elliot \& Friedman (2007) for an expanded discussion of goal based PPA). Although other goal researchers have developed similar methodologies, such as personal strivings (Emmons, 1986), life tasks (Cantor, 1990), and current concerns (Klinger, 1977), individual personal projects are considered to conceptually encompass these 
constructs (Little, 2007). Furthermore, the flexibility and modular nature of the PPA has lent itself to becoming an increasingly popular method to study individual goals (Little \& Gee, 2007).

Several methods exist by which personal projects can be examined. Commonly, the first step in a PPA is the evaluation of all project listed and, after careful consideration, the categorization of projects into domains. Little (1983) reports that the common domains present within his college student samples include: academic, interpersonal, intrapersonal, recreational/hobbies, reading/cultural, gifts/holidays, travel, environmental adaptation, vocational, home activities, spiritual, and health/body. Although typical for the university samples collected by Little in the 1980s, other identifiable personal project domains are possible depending on the sample surveyed and the research question being asked. More recently (Little \& Gee, 2007), a list of most frequently mentioned domains across PPA studies was created. This list of domains is more concise than the original Little (1983) domain categories but is reflective of the level of the range of specificity by which one can evaluate domains within a PPA. The Little \& Gee (2007) condensed list of domains includes: interpersonal, academic, work, intrapersonal, recreational/leisure, health, maintenance, and other.

Little (1983) and Little \& Gee (2007) emphasize that the choice of domain focus is based upon researcher interests and the research question being posed. For example, more specific personal project domains can be examined within the interpersonal domain, such as the family domain or the friends domain (as is reflected within the Little (1983) list of domains). One potential criticism of this 
approach is that the researchers instead of participants are commonly used to assess the domain to which each personal project belongs. This process of domain classification is most commonly accomplished using two independent raters, after which intterater reliability estimates are calculated (typically exceeding $90 \%$ rater agreement) (e.g., Little \& Gee, 2007; Nurmi \& Salmela-Aro, 2002; Salmela-Aro \& Nurmi, 1997a; b; 2004). Although participants are not typically used to evaluate the domain to which each personal project belongs, this approach limits the degree of response bias due to the number of participants not equaling the number of raters.

When viewed from a self-regulation perspective, personal projects are conceptualized by Little (1999) as comprising primarily mid-level "do goals" and may be further classified across individual ratings on any number of dimensions. Little suggests that the following fifteen dimensions are of use: importance, enjoyment, value congruency, self-identity, absorption, control, initiation, time adequacy, visibility, other's view, progress, outcome, stress, difficulty, and challenge. These dimensions are different than the researcher derived domains mentioned above, and are means by which participants can rate their personal projects. More recently, Little \& Gee (2007) suggest the use of seventeen cognitive dimensions including: importance, difficulty, visibility, control, responsibility, time adequacy, outcome/likelihood of success, self-identity, other's view, value congruency, progress, challenge, absorption, support, competence, autonomy, and stage. Additionally, Little \& Gee suggest the use of the following 10 affective dimensions: sad, fearful/scared, full of love, angry, happy/with enjoyment, hopeful, stressed, uncertain, depressed, and other emotion. 
Based on empirical analysis and theoretical postulations (Little, 1989; Little \& Gee, 2007; Salmela-Aro \& Nurmi, 1996), individual project ratings on the above dimensions are found to cluster into five higher order themes including: project meaning, structure, community, stress, and efficacy. The meaning theme is comprised of the value congruency and self-identity dimensions. The structure theme is comprised of control, and time adequacy dimensions. The community theme is made up of visibility and other's view of the importance of the project. The stress theme is comprised of the stress, challenge, and difficulty dimensions and the efficacy theme is made up of the progress and anticipated success dimensions. Little and Gee suggest that the five themes derivable from ratings of personal project dimensions are equivalent to traits within five factor theory of personality (Costa \& McCrea, 1992) and that each of the five themes can be used as predictors of outcomes interest. For example, it is generally found that wellbeing is present within individuals whose projects are low in stress and high in meaning, structure, community, and efficacy (Little \& Gee, 2007).

Although PPA commonly includes the above dimensions and 5 factors, the flexibility of the methodology allows for researchers to add additional dimensions of interest (e.g., Little, 1989; Little, 2006), focus on only a small number of dimensions (e.g., Brunstein, 1993), or disregard the dimensional rating procedures altogether (e.g., Nurmi \& Salmela-Aro, 2002). Another potential means by which researchers can examine personal projects is upon an intergoal conflict matrix (also referred to as a cross-impact matrix) (Little, 1983; Little \& Gee, 2007). Following the initial elicitation of personal projects by the participant, a matrix can be 
constructed upon which projects are listed on both the horizontal and vertical axes. In so doing, participants are able to rate the degree to which each project conflicts with the other projects. This matrix not only allows for the evaluation of conflict present between project ' $a$ ' and project ' $b$ ' but also project ' $b$ ' and project ' $a$.' Although seemingly trivial, this distinction allows for the intergoal conflict matrix to capture important distinctions in goal conflict such as WFC and FWC.

Yet another method of assessing personal projects is through the domains present within the PPA. The typical personal project domain approach assumes that the frequency of a particular personal project domain within the PPA indicates that domain's importance (Salmela-Aro \& Nurmi, 1997c). As such, a tally of domains present within a PPA's elicited personal projects yields a ranking system by which project domains can be compared. For example, an individual with the listed personal projects of: 1.) go visit my mother 2.) spend more time with my siblings 3.) write my grandmother a letter and 4.) visit the grand canyon, might have their project domains tallied as: three projects related to the family domain and one personal project related to the travel domain.

The flaw of the tallying approach to personal project domain assessment is that domain frequency does not necessarily indicate domain importance. For example, an individual may have the following personal projects: 1.) Study for my upcoming psychology exam, 2.) Get along better with my roommate, 3.) Get all of my readings done before each class, and 4.) Take care of my sick mother. Although the frequency of the academically related personal project domain is greater than the family or friends domains, it is plausible that the personal project of caring for 
one's sick mother is seen as being more important than studying for an upcoming exam or completing assigned readings. Whether or not this is the case is likely to vary but does highlight the problematic nature of this frequency approach to analyzing personal project domains.

Outcomes Associated with Personal Projects. Although only in existence for a little over two decades, PPA has been used in a wide array of studies ranging from universities to work-place settings. Due to the diverse populations, settings, and methodological approaches under which PPA has been studied, the scope of this paper does not allow for a complete review of PPA studies. However, due to this document's goal of examining occupationally relevant outcomes associated with individual personal projects, a review of personal project research into work related outcomes will follow.

One of the earliest attempts to assess work related outcomes using the personal projects analysis was undertaken by Yamamoto et al., (1992) in their study of 14 Japanese university students transitioning to work. The authors examined change in personal project domain frequency over time, specifically during pretransfer and post-transfer to the workplace periods. Identified domains within the PPA conducted by Yamamoto and colleagues include: profession, personality/selfactualization, leisure and hobby, and other. As hypothesized, frequency of personal project domains elicited changed across an eight month time lag between data collections. Specifically, Yamamoto and colleagues found that during this transition, an overall decrease in the number of leisure and hobby domain projects occurred and an increase in the number of professional domain projects was 
observed. Additionally, a decrease in the amount of reported conflict between personal projects between the pre-transition and post-transition periods occurred. The findings of Yamamoto and colleagues (1992) are interesting but difficult to interpret due to the low $n=14$ sample size.

In a similar line of research, Nurmi, Salmela-Aro, and Koivisto (2002) examined longitudinally the relationship between personal project/goal importance, achievement beliefs, and emotions during the transition between school and work. For this study, 250 vocational and technological school students in Finland were followed over a period of one and a half years and assessed three times. At all three collection times, Nurmi et al. (2002) instructed participants to focus only upon work related personal projects. In this manner, Nurmi and colleagues avoided the researcher based classification of projects into domains. Also as part of the PPA, participants responded to how each of their work goals were rated along the following eleven dimensions: importance, accomplishment, absorption, progress, procedural knowledge, capability of achievement, means, stress, difficulty, negative feelings, and positive feelings. Based on these eleven dimensions, three mean factor scores of project importance (importance, absorption), achievement (accomplishment, progress, procedural knowledge, capability of achievement, and means), and positive emotion (stress, difficulty, negative feelings, and positive feelings) were obtained.

Nurmi and colleagues' (2002) results supported that individual appraisals of work related personal project importance prior to leaving school predicted success in finding employment. Additionally, individuals that appraised themselves as 
having the means to achieve their transition goals were most likely to be employed just after graduation as well as one and a half years later. For those students that decided on continuing their education rather than entering the work force, decreased appraisals of work related project importance was observed one and a half years after graduation. This decrease in work domain projects is likely to reflect a goal disengagement from individually held work goals and a reengagement in alternative educational goals. This finding suggests that goal disengagement and goal reengagement coping are actively used when goal conflict is experienced.

Utilizing the same sample described in the Nurmi, Salmela-Aro, and Koivisto (2002) study, Nurmi and Sammela-Aro (2002) further examined the relationship of work related and nonwork related personal projects to well-being (measured by the Beck Depression Inventory (Beck, et al., 1961)) and employment success (unemployed vs. employed). As part of their PPA, Nurmi and SammelaAro categorized personal projects into the domains of education, work/occupation, family, and self. At the second data collection point (3 months post-graduation) and the third data collection point (5 months after second collection) frequency of projects within the work domain failed to predict employment success, whereas family domain project frequency effectively predicted employment success.

Frequency of education, work/occupation, family, and self personal project domains failed to consistently predict well-being across all three data collection points (Nurmi \& Samela-Aro, 2002). Depressive symptoms decreased at collection time two for individuals that were employed full-time and reporting more work related projects but this relationship was no longer significant at data collection 
time three. Although promising, these results are difficult to interpret. The authors suggested that having goals consistent with major life challenges and demands (transition to work) currently being faced may promote well-being. This interpretation makes sense but fails to account for the absence of a significant relationship between work personal project domain frequency and employment success at times two and three or the absence of a significant relationship between well-being and work related project domain frequency at data collection time three. In addition to studies exploring PPA in relation to career transitions, several studies have examined the relationship between personal projects and workplace outcomes. One such study, by Maier and Brunstein (2001), expanded upon Brunstein's (1993) findings of goal commitment's moderating effect on perceptions of goal attainability and subjective well-being. Using a sample of 81 German organizational "newcomers" (employees having tenure of 20 weeks), Maier and Brunstein explored the effect of goal commitment and perceived attainability on organizational commitment and satisfaction. Participants in this study listed four of their long-term work goals at time one and rated each of these goals upon PPA dimensions pertaining to perceived goal attainability and perceived goal commitment. At times two (four months later) and three (eight months later) participant were again questioned regarding the progress they had made toward their four work related goals. In addition to the perceived goal progress, job satisfaction and organizational commitment were assessed at times two and three.

Findings from the Maier and Brunstein (2001) study indicated that goal commitment and goal attainability interacted significantly to account for 
newcomers' job satisfaction and organizational commitment. Specifically, it was found that increases in job satisfaction and organizational commitment were experienced for employees that were committed to their goals while perceiving their work environment as being conducive to goal attainment. This effect was stable across collection points at time two and three. Furthermore, goal progress mediated the effect of the goal attainability $\mathrm{x}$ goal commitment interaction on newcomer job satisfaction and organizational commitment at times two and three. These findings suggest that when individuals perceive high levels of goal progress, the impact of goal attainability and goal commitment are less influential. Additionally, this study suggests that organizational newcomers observing high degrees of workplace afforded goal progress will have greater positive associations with their workplace (organizational commitment and job satisfaction). As such, these findings fit nicely within a self-regulation framework.

Wiese and Fruend (2005) also used PPA to assessed the effect of goal progress on job satisfaction within a sample of German professionals. Following a similar procedure to Maier and Brunstein (2002), Weise and Fruend instructed their participants to generate five goals pertaining to their work. At both time one and time two (three years later) participants reported levels of well-being (positive and negative affectivity), job satisfaction, goal progress, and goal difficulty (subjective appraisal of expected level of difficulty to goal completion). Unexpectedly, after having controlled for time one levels of dependent variables, goal progress did not predict either well-being or job satisfaction. Goal difficulty however, significantly predicted change in job satisfaction and well-being at time two. 
Taken as a set, this comprehensive review of occupationally relevant PPA studies not only highlights the variability of methods employed during PPA but also the relative lack of research on personal projects within the workplace. Of the five published studies that assessed personal projects within the workplace, only two examined additional personal projects in addition to other work related projects (Nurmi \& Sammela-Aro, 2002; Yamamoto et al., 1992) and of these two studies, only Nurmi and Sammela-Aro had a sample large enough to effectively examine its hypotheses.

\section{Goal Conflict}

Until recently (Edwards, 1998; Emmons \& King, 1988; Karoly \& Ruehlman, 1996; Locke, et al., 1994; McKeeman, \& Karoly, 1991), goal theorists had not addressed the issue of what happens when one goal conflicts with another goal in an individual's hierarchy. The available literature has examined the goal conflict phenomenon from one of two perspectives. The first method of assessing goal conflict entails a bipolar assessment strategy, in which researchers assume that an absence of goal conflict equates to a presence of goal facilitation (e.g., Kehr, 2003). The second method of goal conflict research examines goal facilitation and goal conflict as being unipolar and separate dimensions. Specifically, the second method of analysis suggests that it is possible for a goal to simultaneously be in conflict with and facilitate another goal. An example of this type of relationship can be seen in an individual's goal to work out three times a week and the individual's goal to get promoted at work. It is possible that an exercise goal may be perceived as helping an individual deal with the long hours and stresses 
associated with the workplace, whereas the time commitment associated with exercise might conflict with one's required time to complete work tasks. Research into both the bipolar and unipolar/two dimensional nature of goal conflict supports the separation of goal conflict and goal facilitation into two dimensions, each representing high and low values of the construct respectively (Riediger, 2007). As the focus of this paper is on goal conflict, the following review of literature will focus on outcomes associated with goal conflict but will include studies examining goal conflict using unipolar and bipolar conflict scales.

Using a sample of college students, Locke, et al. (1994) studied the effect of conflicting assigned goals, such as increasing one's productivity (quantity), while simultaneously increasing the quality of the product. Locke and colleagues found that the conflict between assigned goals resulted in a decrease of overall performance (output quantity) and in a follow up study examined the goal conflicts common among university faculty: producing publications and providing quality teaching. Within this follow up study, Locke and colleagues found that a conflict between publishing and teaching goals resulted in lower research productivity. Although Locke's research highlights the deleterious effects of conflicting assigned goals, the research does not examine the effect of conflict among goals which are not assigned by a third party and are instead self-identified.

Emmons and King (1988) examined outcomes associated with conflicting personal strivings. Personal strivings are conceptualized as being "goals that lie directly behind individuals' behavioral choices (i.e., 'what an individual is characteristically trying to do')" (p.1041). Examples of such personal strivings 
might include 'seek out new and more interesting friends' and 'have a more equitable relationship with spouse.' After having eighty-eight undergraduate participants elicit 15 personal strivings and rate the degree to which each striving was in conflict with each other, Emmons and King assessed the degree to which inter-goal conflict was associated with psychological and physical well-being. Counter to expectations, Emmons and King found that only physical well-being was associated with increased goal conflict among personal strivings and that conflicting personal strivings were not significantly associated with decreased psychological well-being.

In a similar study, McKeeman and Karoly (1991) examined the effect of goal conflict upon individuals attempting to quit smoking. Participants were instructed to provide a rank ordered list of their eight most important goals. Following a similar method used in the Emmons and King (1988) article, participants then rated the degree to which each of their goals were in conflict with one another (Little, 1983). McKeeman and Karoly found that the degree to which participant's non-smoking goals conflicted with goals to quit smoking, effectively predicted the success of short-term and long-term smoking cessation.

Karoly and Ruehlman (1996) extended the McKeeman and Karoly (1991) methodology to assess outcomes associated with work and nonwork goal conflict. After having participants identify their two most important work related goals and their single most important nonwork related goal, participants were then instructed to rate the degree to which each of their goals were in conflict. Interestingly, work goals conflicting with one another were not found to significantly predict 
psychological well-being (depression or anxiety), whereas work-nonwork goal conflict was found to significantly predict both depression $(r=.21, p<.01)$ and anxiety $(r=.26, p<.01)$. Unfortunately, Karoly and Ruehlman did not report what specific nonwork goals were most prevalent, nor did they supply the rates for particular types of nonwork goals. It could be that nonwork goals mentioned all centered around one's family, in which case, this research would be more representative of the goal based (WFC) literature (discussed below). This methodological shortcoming was again found in the Karoly et al. (2005) study examining exercise-non-exercise goal conflict.

Recently, Kehr (2003) examined longitudinally whether enduring goal conflict and goal facilitation (instrumental goal relations) were associated with amounts of positive and negative affect among a sample of German managers undergoing training on goal setting techniques. At time one, participants rank ordered six of their current goals and using a two dimensional goal matrix, rated the degree to which each goal was in conflict with the other five goals. This method resulted in conflict scores, which were then aggregated across goals, with lower scores indicating 'instrumental goal relations' (goal facilitation) and higher scores indicating 'very strong goal conflicts' (goal conflict). At time one, no significant relationship between goal conflict and either positive or negative affect was found. Amount of goal conflict at time one did not predict time three (nine months later) positive or negative affect (no information was given concerning time 2 measures taken at six months post time 1 collection). Correlation analyses did support that time three goal conflict predicted the degree to which the managers felt time three 
negative affect $r=.21, p<.05$, but not positive affect. However, regression equations did not support the hypothesis that duration of goal conflict was associated with either positive or negative affect. After having controlled for previous levels of affect and goal conflict, a significant $23 \%$ of the variance in positive affect $F=6.69, p<.001$ was predicted by the interaction of time one and time three goal conflict but, once examined more closely, was explainable by goal conflict occurring after time one, rather than enduring goal conflict that originated at time one.

Kehr (2003) also found that attainment of one's goals significantly moderated the relationship between goal conflict and positive affect $\beta=-.17, t(90)$ $=-2.21, p<.05$ but this relationship was non-significant for negative affect. Specifically, increases in the attainment of conflicted goals was associated with increases in positive affect, but no similar decrease in negative affect was experienced for individuals high or low in goal attainment. This study's overall counterintuitive findings may be due to the relatively low $n=99$ used to test its hypotheses and the potentially confounding nature of the participants' concurrent goal focused training program.

The above studies are a thorough review of research examining goal conflict. As can be seen, despite the importance of goal conflict, relatively few studies have actually examined its outcomes. Although these studies establish that goal conflicts inhibit one's ability to successfully pursue desired goals, they do not examine the influence of occupationally relevant goal conflicts such as work family 
conflict or more broadly work-life conflict (with the possible exception of Karoly \& Reuhlman, 1993).

Kehr (2003) did examine the effect of general goal conflict among a population of managers but specific conflict between work goals or between work goals and nonwork goals was not examined. Similarly, Emmons and King (1988) examined goals that spanned all life contexts and did not focus on the importance of any particular type of goal conflict. McKeeman and Karoly (1991) and Karoly and Reuhlman (1993), on the other hand, did focus on one particular type of goal conflict (other goals vs. smoking cessation goal and work goal vs. nonwork goal) and as such can be seen as an important step to understanding specific types of goal conflict. Unfortunately, this type of goal specific approach to goal conflict has not been undertaken in order to understand specific goal conflicts present within the work and nonwork domains. The closest that the goal conflict literature comes to this type of occupationally specific goal conflict analysis is Locke, et al. (1994). This being said, Locke and colleagues did not examine goal conflicts existing outside the work context and ultimately did not examine goals that individuals independently rated as being most important.

Work-Family Conflict. WFC is commonly defined as "a form of interrole conflict in which the role pressures from the work and family domains are mutually incompatible in some respect. That is, participation in the work (family) role is made more difficult by virtue of participation in the family (work) role" (Greenhaus \& Beutell, 1985, p. 77). Drawing from the work of Kahn et al., (1964), Greenhaus and Beutell framed WFC in terms of three major role conflicts: time based 
conflicts, strain based conflicts, and behavior based conflicts. Time based conflicts were considered to be present in situations where multiple roles compete for an individual's limited time resources. Strain based role conflict occurs when strains, such as fatigue, anxiety, and depression, arising from one role impact one's performance in another role. Behaviorally based role conflict is considered to be present when individuals are expected to display types of behaviors within one role that may not be compatible within other roles. As such, behaviorally based role conflict is considered to occur when an individual is unable to successfully identify and transition between acceptable behaviors across different roles.

When considered from a self-regulatory perspective, time based, behavior based, and strain based work family role conflicts are explainable from a goal-based perspective (Edwards, 1992). As an individual's available time to devote towards one goal impedes upon available time to devote to another goal, goal conflict is likely to occur. As such, time based role conflict stress is equivalent to the stressor of goals conflicting due to limited time resources. Behaviorally based role conflicts, on the other hand, are comparable to individuals using incompatible coping strategies across goals. For example, although a confrontational coping style may be appropriate for making progress toward certain work goals, similar confrontational coping behavior may be seen as undesirable when attempting to progress toward family related goals. Strain based role conflict is also explainable from a self-regulatory perspective. Whereas behaviorally and time based role conflicts are comparable to self-regulatory feedback processes, strain based role conflicts arise from the experienced strain resulting from the prolonged stress of 
inadequate goal progress. A good example of this goal-role strain relationship can be seen in nurses experiencing burnout due to poor work goal progress and subsequently experiencing poor performance on family related goals.

Interest in WFC and FWC has increased over the last thirty years due in large part to major shifts occurring within the working class. Specifically, within the United States the occurrence of single parent households has more than doubled and the frequency of single parents working within these households has increased by more than $20 \%$. Similarly, the number of dual earner households has nearly doubled over the last thirty years (Bellavia \& Frone, 2005). Clearly, conflicting work and family goals existed prior to the 1970s but the recent shift in the prevalence of working parents and spouses has underscored the need to study WFC and FWC.

Although a complete review of WFC/FWC outcomes is beyond the scope of this paper (for a review see Belavia \& Frone, 2005), the link between individual and organizational outcomes and WFC/FWC is well established. Individual outcomes relating to physical and psychological well-being, such as dissatisfaction with life, alcohol consumption, depression, and decreased physical health, have been well documented (e.g., Frone, Russell, \& Cooper, 1997; Grzywacz, 2000; Perrewé, Hochwarter, \& Kiewitz, 1999). Furthermore, occupational outcomes, such as decreased job satisfaction, turnover intentions, and absenteeism have been associated with WFC/FWC (Anderson, Coffey, \& Byerly, 2002).

When examining organizational outcomes associated with WFC and FWC, FWC seems to be more strongly related to employee productivity than does WFC. 
Turnover intentions, however, tend to have a stronger relationship with degree of WFC experienced (Kossek \& Ozeki, 1999). Frequently, organizational outcomes (e.g., job satisfaction and organizational commitment) are more strongly associated with WFC, whereas family oriented outcomes tend to be more related to FWC (Balmforth \& Gardner, 2006; Frone, Yardley, \& Markel, 1997; Netemeyer, Boles, \& McMurrian, 1996). Similarly, antecedents of both WFC and FWC tend to be most associated with the direction of conflict, such that work related conflict is more related to work related antecedents and family related conflict is associated more with family related antecedents (Byron, 2005; Ford, Heinen, \& Langkamer, 2007).

Recently, a shift in terminology has recast the WFC/FWC literature into the newly labeled Work-life conflict (WLC). The shift in terminology from workfamily to work-life was undertaken in order to more inclusively represent the nontraditional, blended, and gay and lesbian families, as well as the unique issues that are present within these families' work and family contexts (Barnett, 1999). As the emphasis of work-family/work-life research is on the interrole conflicts present between work and family domains, this new conceptualization attempts to encompass a broader definition of the life role. Although sounding more inclusive of other nonwork related roles and contexts, the work-life literature still focuses almost exclusively on traditional WFC and FWC. Despite this, repeated calls have been made to explore non-family goals and how these goals may conflict with work goals (Bellavia \& Frone, 2005; Edwards, 1998). 
Initial attempts have been made to examine WLC arising from outside of one's direct family. These handful of studies have begun to consider the WLC within broader contexts such as elder parent care (e.g., Barling, MacEwen, Kelloway, \& Higginbottom, 1994) and general work-nonwork conflict measures assessing the degree to which one's nonwork roles (including family) conflict with one's work role (O'Driscoll, Ilgen, \& Hildreth, 1992; Wiley, 1987). Unfortunately, none of these studies have attempted to assess specific nonwork roles, such as friends, academics, social life, and self-care, conflict with one's work role within an adult population. Instead the studies assessing general work-nonwork conflict use measures which assess nonwork contexts only in terms of "outside of work" (O’Driscoll, Ilgen, \& Hildreth, 1992; pg. 279) and do not differentiate between family and non-family nonwork roles.

Work-Academic Conflict. Although not as thoroughly studied as WFC or FWC, work-academic conflict (WAC) includes an additional domain, which is important to consider when examining goal conflict's relationship to individual well-being. Similar to WLC, WAC can be conceptualized as conflicting goals within the work and academic domains. Despite the WAC literature's exclusive examination of work's impact on high school students, similar WAC outcomes may be expected from an older adult sample employed while enrolled at university. As a result, a review of the WAC literature is included below.

Commonly cited as one of the earliest attempts to examine the impact of WAC, Greenberger, Steinberg, and Vaux (1981) compared two-hundred employed high school students with three-hundred and nineteen unemployed students. 
Although not assessing WAC directly, the comparison between unemployed and employed students reveled that girls employed part-time were more likely to be absent from school and both employed boys and girls working under stressful job conditions were more likely to consume alcohol and marijuana. Interestingly, greater well-being (fewer somatic complaints and psychological symptoms) was found for boys employed in stressful jobs and work stress appeared to act as a moderator of employment and well-being. Although this early attempt to assess WAC yielded interesting results, WAC itself was not directly assessed and potential alternative explanations exist for this study's findings. For instance, perhaps those students that are unemployed belong to families less supportive of drug and alcohol use.

When examining the antecedents to WAC, Wirtz, Rohrbeck, Charner, \& Fraser (1988) found that the number of months employed (tenure) and average weekly number of hours employed interacted to predict high versus low WAC. Specifically it was found that for the 457 high school students surveyed, students with the highest tenure and fewest average weekly hours worked reported the lowest levels of WAC. For this study, WAC was assessed using a one item measure "my job interferes with my work," to which participants' ratings ranged from 'agree strongly' to 'disagree strongly.'

Mortimer and Finch (1992) examined the gender differences for WAC outcomes. Specifically, in their study of 1,001 ninth graders, girls reporting greater WAC tended to also report significantly lower self-esteem $(ß=-.255, p<.001)$, greater depressive affect $(\beta=.305, p<.001)$, and reduced general psychological 
well-being ( $(\beta=-.208, p<.001)$. Conversely, employed boys reporting high WAC did not experience similar outcomes. For their research, Mortimer \& Finch assessed WAC using a four item measure assessing the degree to which the student's job interferes with homework completion, preparedness, school attendance, and concentration (fatigue).

When examining a time based conceptualization of WAC (i.e., time at work interferes with time at school), Barling, Rogers, \& Kelloway (1995) found that their sample of 233 part-time employed high school students reporting the greatest amounts of WAC tended to have lower grades $(r=-.44, p<.05)$, decreased selfesteem $(r=-.18, p>.05)$, and less time spent on homework $(r=-.31, p<.05)$. After controlling for student age and number of hours worked in the first step of the regression and inputting hours worked and role conflict experienced in the second step, role conflict still accounted for unique variance in number of classes cut $(B=$ $.22, p<.01)$ (no bivariate correlation for classes cut is available) and self-esteem ( ( $=-.31, p<.01)$.

Most recently (Markel \& Frone, 1998), WAC antecedents and outcomes were examined using structural equation modeling. Antecedents including workload, job hours, and job dissatisfaction were chosen for the analysis, as were the outcomes of school readiness, school performance, and school dissatisfaction. Findings from the analysis indicate that workload, job hours, and job dissatisfaction all significantly contribute to WAC, which in turn contributes to school readiness, then school performance, and finally school dissatisfaction. In the nearly ten years since Markel and Frone's publication, no known research has been published on the 
topic of WAC. Furthermore, no research has been conducted outside of the high school setting in order to examine WAC.

One theoretical perspective which might help guide future researchers in the area of work-nonwork conflict is Edwards (1992) cybernetic theory of work stress. As an expansion of the self-regulation framework focusing specifically on the workplace goals and workplace related stress, the cybernetic theory of work stress views all goals within a self-regulatory hierarchy as being potentially in conflict with one another. Edwards (1998) proposed an extension of this cybernetic theory of work stress to include goal conflict as an explanatory mechanism by which WFC, FWC, and WAC can be understood. When viewed from this perspective, individual work related goals such as 'I want to be a good employee' may conflict with family goals of 'I need to pick up the kids from soccer practice' and vice versa. In order to further contribute to the above lines of goal conflict research, the use of a self-regulatory perspective is proposed as a means to guide a more thorough examination of conflicting work and nonwork personal project domains. By viewing PPA from a self-regulatory perspective, the interrelationships between goals and effectiveness of self-regulatory coping strategies, such as disengagement and reengagement, can be assessed in relation to intergoal conflict. Through the exploration of outcomes associated with conflicts between work goals and specific domains present within nonwork goals, this research will significantly contribute to the expansion of the work-life conflict literature to include goal conflicts beyond WFC, FWC, and WAC. As a result of the exploration of potential work-nonwork goal conflicts and the effectiveness self-regulatory coping strategies at ameliorating 
conflict associated stress, prospective intervention strategies can be created by which individuals may be able to better cope with work related goal conflict. In order to address these issues, the following studies were conducted. 


\section{Pilot Research}

Following the suggestions and methodologies of previous PPA, pilot data was collected within a student sample of convenience $(n=31)$ at a large Midwestern commuter university. The resulting sample was comprised of $74 \%$ females and $26 \%$ males, with $71 \%$ of the sample employed at least part-time. The goal of this pilot data was to assess the types of projects and project domains present within this university setting. Replicating previous research methodologies for personal project domain analysis (Little, 1984; Little \& Gee, 2007; Nurmi \& Salmela-Aro, 2002), classification of personal projects domains was accomplished using two psychology graduate students. Each graduate student separately identified personal project domains present within the pilot data and then compared number and type of domain categories with the other graduate student. Upon initial comparison, interrater agreement for the sample's derived personal project themes was $79 \%$. Initial differences in identified personal project domains included the domains of illness, environmental (e.g., moving, cleaning apartment), and self-goals (e.g., selfexploration, creation of identity). Following an evaluation of rater differences, environmental projects were reconciled with the organization/cleaning domain, illness related projects conceptually overlapped with the self-care domain, and selfgoals were synonymous with projects within the identity domain. Additionally, the domains of friends, hobbies/freetime, and significant other were collapsed into the 
"social domain" in order to reduce conflicting categorizations. Following this reconciliation of domain discrepancies, interrater agreement reached $100 \%$. This pilot study yielded the following fourteen personal project domains: friends, family, significant other, achievement/academic, self-care, identity, free time/hobbies, organization/cleaning, financial, job/occupation, religion/spiritual, extra-curricular, transition, and transportation.

Personal projects contained in the pilot data were then independently categorized using the domains derived from the above mentioned graduate student exploration of the data. An upper level undergraduate psychology student and a graduate student in psychology separately coded the pilot data according to the above derived domains. For this process, an interrater agreement of $91 \%$ was achieved. From this categorization, an estimation of this sample's most commonly mentioned project domains was achieved. In rank order, the most common project domains present within this sample included: academic (mentioned 82 times; 22\% of projects), social (mentioned 80 times; $22 \%$ of projects), self-care (mentioned 57 times; $15 \%$ of projects), organization/cleaning (mentioned 39 times; $11 \%$ of projects), job (mentioned 28 times; $8 \%$ of projects), family (mentioned 22 times; $6 \%$ of projects), transition (mentioned 22 times; $6 \%$ of projects), financial (mentioned 17 times; $5 \%$ of projects), identity (mentioned 10 times; $3 \%$ of projects), transportation (mentioned 7 times; $2 \%$ of projects), religion (mentioned 4 times; $1 \%$ of projects), and extra-curricular (mentioned 4 times; $1 \%$ of projects). Based on the above literature review and this initial exploratory work concerning student projects, the following study is proposed. For the purposes of the current 
study, hypotheses and methodological choices are based upon the categories derived from this initial collection of personal project domains. 


\section{The Present Study}

The goals of this research are two-fold. First, it was hoped that through the use of PPA, an expanded view of WLC would be achieved. This expanded view includes the conceptualization of WFC and FWC as conflicting work and family goals as suggested by Edwards (1998). Additionally, this study's expansion of previous WLC literature assessed the degree to which specific work-nonwork conflicts (including but not limited to WFC/FWC) contributed to individual wellbeing. Due to the dynamic nature of individual goals, it was expected that a goalbased approach to understanding WLC would account for more variance in participant well-being than the previously used role based measures of WLC.

Second, this research attempted to expand previous occupational research into the self-regulatory coping strategies of disengagement and reengagement coping (McKee, et al., 2006; 2007). Based on McKee and colleagues' research as well as Wrosch et al., (2003), increased well-being was expected to be associated with individual differences in the predisposition to disengage completely from unattainable goals or reengage in other achievable goals prior to or following goal disengagement. As such, this study attempts to expand previous research into disengagement and reengagement coping by assessing whether self-regulatory coping styles moderate the relationship between goal conflict and well-being. 
Due to the decreased rate of goal progress associated with conflicted goals, reduced physical and psychological well-being, as well as decreased job attitudes are likely to exist (Little, 2007; McKee, et. al., 2007). The following hypotheses test the relationship of inter-goal conflict and goal directed coping as they relate to outcomes of interest common to studies examining WLC. Outcomes of interest include measures of physical well-being (physical symptoms), psychological wellbeing (positive and negative affect), and job attitudes (job satisfaction and turnover intentions). Although turnover intentions do not directly fit this categorization, for the purpose of the following hypotheses, the above outcomes will be referred to collectively as participant well-being.

\section{Hypothesis 1}

In order to replicate the limited literature on work-nonwork conflict (Karoly \& Reuhlman, 1993), measures of conflicting work and global nonwork (W-GNW) and global nonwork-work (GNW-W) personal projects will be examined. Similar to Karoly and Reuhlman's findings with work-nonwork conflict, this study predicts a negative relationship between participant well-being and degree of W-GNW conflict experienced (Hypothesis 1a). In order to expand beyond the Karoly and Reuhlman research, this study further hypothesizes that GNW-W conflict will predict lower levels of well-being (Hypothesis 1b).

\section{Hypothesis 2}

Specific work-nonwork conflicts of work-family, work-social, workacademic, and work-self-care may be associated with lower levels of perceived goal 
progress. Self-regulation theory suggests that lower levels of perceived goal progress is associated with negative affect (Carver \& Scheier, 1999). As such, it is hypothesized that specific types of work-nonwork conflicts will predict lower levels of well-being (Hypothesis 2a). Similarly, specific nonwork-work conflicts are hypothesized to predict lower levels of well-being (Hypothesis 2b).

\section{Hypothesis 3}

As the current research into WLC focuses on conflicts more representative of WFC, it is necessary to examine whether consideration of further life conflict domains allows for greater prediction of employee well-being. As such, this study hypothesizes that specific work-nonwork and nonwork-work domain conflicts will predict participant well-being beyond a widely used WFC and FWC scale (Netemeyer, Boles \& McMurrian, 1996).

\section{Hypothesis 4}

Based on previous research into disengagement and reengagement coping (Wrosch, et al., 2003), it is expected that individuals more likely to utilize disengagement and reengagement coping strategies in the face of low goal progress will experience increased well-being compared to those less predisposed to use disengagement and reengagement coping. As goal conflict is likely to produce lower than acceptable perceived goal progress (Little, 2007; McKee, et. al., 2007), individual differences in goal disengagement and goal reengagement coping strategies are hypothesized to serve as effective moderators of W-GNW conflict and participant well-being (Hypothesis 4a). Similarly, goal disengagement and goal 
reengagement coping strategies are hypothesized to serve as effective moderators of GNW-W conflict and participant well-being (Hypothesis 4b).

\section{Hypothesis 5}

Specific measures of work-nonwork goal conflict are also expected to be moderated by individual predispositions to employ disengagement and reengagement coping. As was seen in the pilot study, participants' most frequently mentioned nonwork personal project domains are academic and social. As the financial demands of university necessitate employment for many students, it may be that individuals predisposed to use disengagement and reengagement coping within the more flexible work-social personal project domain will experience increased well-being. Students experiencing high rates of work conflicting with social life may decide to reschedule social activities (limited goal disengagement and goal reengagement coping). As such, goal disengagement and goal reengagement coping strategies are hypothesized to serve as effective moderators of work-social conflict and participant well-being. (Hypothesis 5a). Additionally, it is hypothesized that goal disengagement and goal reengagement coping strategies are expected to serve as effective moderators of social-work conflict and participant well-being. (Hypothesis 5b).

\section{Hypothesis 6}

As the academic domain was most frequently mentioned by participants in the pilot study, it may be useful to determine whether predispositions to use either disengagement or reengagement coping strategies moderates the relationship between work and academic domain conflicts. As academic and work domain 
conflicts are likely to result in lower than desirable goal progress, goal disengagement and goal reengagement coping strategies are hypothesized to serve as effective moderators of work-academic conflict and participant well-being (Hypothesis 6a). Similarly, goal disengagement and goal reengagement coping strategies are hypothesized to serve as effective moderators of academic-work conflict and participant well-being (Hypothesis 6b).

This research will have both practical and theoretical implications. Through the examination of multiple work-nonwork conflict domains, practitioners interested in reducing employee stress can identify the most problematic sources of work-nonwork conflict. Once identified, interventions beyond the now common "work-family friendly policies" become possible. Such interventions could include allowing flextime for employees that are currently enrolled in school or the greater inclusion of health-oriented facilities within the workplace.

From a theoretical standpoint, this study expands the current WFC/FWC and WAC literature in two ways. First, this study is unique in its examination of work family and work-nonwork conflict in terms of goal conflict. This conceptualization of role conflict from a goal-based perspective has been previously hypothesized (Edwards, 1998) but, to the best of my knowledge, never examined. Second, this research contributes to the current literature on WFC and FWC through the addition of further potentially important areas of work-nonwork domain conflict. In order to accomplish these tasks, the following study was conducted. 
Method

\section{Participants and Procedures}

Over the course of two academic quarters, two hundred and twenty-nine employed participants were recruited from the general undergraduate psychology population at a large Midwestern university. Participants worked an average of 24 hours each week and had an average tenure of 15 weeks. The sample was $67 \%$ female and reported having jobs within the retail (37\%), food service (27\%), healthcare $(8 \%)$, assembly $(2 \%)$, caseworker $(3 \%)$, and "other" $(24 \%)$. As such, this sample was comprised primarily of individuals placed in low-human capital jobs in contrast to previous samples used in WFC and FWC research (Allen et al., 2000).

Participants were guided through an on-line PPA in which they were instructed to list personal projects within the following domain categories: work, family, social life, academics, and self-care. Participants were asked to provide three personal projects for each of the project domains, resulting in a total of 15 personal projects elicited. Following this elicitation procedure, participants assessed the degree to which each of their three listed work related projects were in conflict with their nonwork related personal projects. This conflict rating process yielded a total of 36 ratings of conflict. Following this initial conflict rating, participants rated the degree to which each of their nonwork related personal 
projects were in conflict with their work related personal projects. This process again yielded 36 conflict ratings, resulting in a total of 72 conflict ratings.

In addition to the projects elicited and conflict comparisons made, participants filled out measures of self-regulatory goal disengagement and goal reengagement coping strategies, physical and psychological well-being, job satisfaction, turnover intentions, and general demographics. The total time for participants to complete this set of questionnaires did not exceed 1 hour.

\section{Measures}

Work-Nonwork and Nonwork-Work Conflict. Participants were instructed to assess the degree to which each of their work goals is in conflict with their nonwork goals and the degree to which each of their non-work goal is in conflict with their work goals. Project conflict was rated on a scale ranging from $0=$ 'none' to $4=$ 'a great deal.' The resulting seventy-two conflict ratings were grouped into specific types of conflict and summed (i.e., all work-family project conflict scores were added together). This process resulted in separate values for specific worknonwork and nonwork-work conflict (e.g., work-academic, academic-work, workfamily, family-work) (Little \& Gee, 2007). This process yielded 4 work-nonwork goal conflict scores and 4 nonwork-work conflict scores for each participant. Each specific work-nonwork or nonwork-work conflict score ranged between 0 and 36, with greater values indicating more conflict. These scores were averaged for each type of conflict resulting in scores ranging between 0 and 4 for each measure of specific conflict. 
Although the primary goal of this study was to examine specific worknonwork conflict domains, assessing the W-GNW conflict scores allowed for a comparison to Karoly and Ruehlman's (1996) study of work and nonwork goal conflict. In order to achieve a measure of W-GNW, the four averaged specific work-nonwork conflict scores described above were summed. Similarly, the four specific nonwork-work conflict scores mentioned above were summed to create a GNW-W conflict measure. Both the GNW-W and W-GNW conflict scores ranged between 0 and 16, with greater values indicating more conflict.

Work-Life Conflict. The Netemeyer, Boles, and McMurrian (1996) measures of WFC and FWC were used in order to assess role based WLC and test hypothesis 3. The WFC and FWC scales developed by Netemeyer and colleagues consists of five items each rated on a seven point Likert-type scale ranging from $1=$ 'strongly disagree' to $7=$ 'strongly agree' (see Appendix B). The average reported Cronbach's alpha for the WFC scale is .86 and .88 for the FWC scale. Higher scores on both the FWC and WFC scales indicate greater conflict.

Goal Disengagement and Goal Reengagement Coping. Individual differences in disengagement and reengagement from goals were assessed using the Goal Disengagement and Goal Reengagement Scale (Wrosch, et al., 2003) (see Appendix D). Goal disengagement was measured with four items assessing the ease with which individuals report being able to reduce effort and commitment toward unattainable goals. Goal reengagement was measured using six items assessing the likelihood of identifying new goals, committing to new goals, and beginning to actively pursue new goals. Items on both the disengagement and 
reengagement scale were measured using a five-point Likert-type scale. Wrosch and colleagues reported reliability statistics for the goal disengagement scale of Alpha $=.76$ and Alpha $=.89$ for the goal reengagement scale and correlation of .34 between the two scales. For both the disengagement and reengagement scales, higher scores indicate a greater likelihood of employing the particular coping strategy.

Self-Report Physical Well-being Measure. The Physical Symptoms Inventory (Spector \& Jex, 1998) allowed participants to rate the degree to which they were experiencing any of 18 different ailments. Participants rated the frequency to which they experience the ailments using a three point Likert-type scale where 1 = 'no I didn't', 2 = 'yes I did but I did not see a doctor', and 3 = 'yes I did and I saw a doctor' (see Appendix E). Although the PSI yields a total score (the number of items rated 2 and above), the scale items are not conceptualized as being parallel forms of the same underlying construct. Instead Spector and Jex view the PSI as a causal indicator scale (Bollen \& Lennox, 1991), rather than the traditional effect indicator scale. As such, no reliability statistic is given. Once participants complete the PSI, researchers can assess the frequency to which participants rate experiencing an ailment and visiting their health care provider or alternatively experiencing an ailment and not seeing a healthcare provider. For the current study, ailments are tallied regardless of whether a healthcare professional was visited. As such, the range of possible scores on the PSI is between 0 and 18 . Positive and Negative Affectivity Scale. The Positive and Negative Affect Scale (PANAS) was used to assess participant state positive and negative affectivity 
(Watson, Clark \& Tellegen, 1988). Participants responded to the PANAS using a five point Likert-type scale, where $1=$ 'very slightly or not at all' and $5=$ 'extremely' (see Appendix F). Participants use this scale to rate mood relative adjectives experienced over the last week. Twenty adjectives comprise the PANAS, ten of which are related to positive affect, while the other ten are related to negative affect. The PANAS internal consistency reliabilities (Cronbach alpha) are reported by its author to range between .86 to .90 for positive affect and from .84 to .87 for negative affect. The correlation between the positive and negative affect portions of the scale are reported to range from -.12 to -.23 .

Job Satisfaction. The three-item measure developed by Cammann, Fichman, Jenkins, and Klesh (1979) was used to assess participant job satisfaction. Items are responded to using a seven point scale ranging from $1=$ 'strongly disagree' to $7=$ 'strongly agree' (see Appendix G). Higher scores on this scale indicate greater job satisfaction. Reported Cronbach's alpha for this scale is .91.

Turnover Intentions. Participant turnover intentions was measured by a three-item scale developed by Meyer and Allen (1991). Items are responded to using a seven point Likert type scale where $1=$ 'strongly disagree' to $7=$ 'strongly agree' (see Appendix H). Higher scores on this scale indicate greater intentions to turnover. Reported Cronbach's alpha for this scale exceeds .80 (Jaros, 1997).

General Demographics. Participants filled out a short demographic form pertaining to participant age, sex, race, class rank, marital status, number of children, type of job, and hours worked each week (see Appendix I). 
Results

Descriptive Statistics

Means, standard deviations, and scale reliabilities were calculated for all scales used in this study (See Table 1). Descriptive statistics and reliability estimates calculated within this study's sample were comparable to those presented in the literature. Exceptions to this include the Goal Disengagement Scale and the PSI. Within the current sample, the reliability estimate for the Goal Disengagement Scale is $\alpha=.53$, whereas published reliability estimates for comparable university samples are $\alpha=.76$. Despite this difference in obtained reliabilities, the current study's obtained means and standard deviations for the Goal Disengagement Scale are comparable to published values (Wrosch, et al., 2003). The sample mean PSI score obtained in this study was higher than previously reported by Spector and Jex (1998). Specifically, the current study's mean PSI score equals 6.5, whereas Spector and Jex report a mean score of 5.4 within their university sample.

Pearson product moment correlations for all variables are presented in Table 2. An examination of this correlation matrix shows several interesting relationships. Of note, goal disengagement coping was found to significantly predict lower levels of participant positive affect $(r=-.22, p<.05)$, and significantly higher work-family and family-work personal project conflict $(r=16$, 
$p<.05 ; r=.14, p<.05$ ). Also of interest, only the specific conflict of work-social significantly predicted turnover intentions $(r=.13, p<.05)$. 
Table 1

Means, Standard Deviations and Intercorrelations of Predictor and Outcome Variables $(N=229)$.

\begin{tabular}{|c|c|c|c|c|c|c|c|c|c|c|c|c|}
\hline & Mean & SD & 1. & 2. & 3. & 4. & 5. & 6. & 7. & 8. & 9. & 10. \\
\hline 1. work-family & 1.17 & .92 & $(.86)$ & & & & & & & & & \\
\hline 2. work-academic & 1.47 & .97 & $.70^{*}$ & $(.86)$ & & & & & & & & \\
\hline 3. work-social & 1.27 & .90 & $.82 *$ & $.69^{*}$ & $(.84)$ & & & & & & & \\
\hline 4. work-self-care & 1.11 & .83 & $.73^{*}$ & $.67 *$ & $.74 *$ & $(.81)$ & & & & & & \\
\hline 5. family-work & 1.15 & .93 & $.81^{*}$ & $.62 *$ & $.68^{*}$ & $.59^{*}$ & $(.87)$ & & & & & \\
\hline 6. academic-work & 1.35 & .97 & $.57 *$ & $.75^{*}$ & $.58 *$ & $.53 *$ & $.72 *$ & $(.88)$ & & & & \\
\hline 7. social-work & 1.30 & .95 & $.74 *$ & $.64 *$ & $.79 *$ & $.59 *$ & $.81 *$ & $.72 *$ & $(.87)$ & & & \\
\hline 8. self-care-work & 1.10 & .86 & $.64 *$ & $.59 *$ & $.61 *$ & $.73 *$ & $.70 *$ & $.69 *$ & $.74 *$ & $(.85)$ & & \\
\hline 9. W-GNW & 4.89 & 3.23 & $.91 *$ & $.86^{*}$ & $.91 *$ & $.87 *$ & $.76^{*}$ & $.69 *$ & $.77 *$ & $.72 *$ & $(.91)$ & \\
\hline 10. GNW-W & 5.03 & 3.31 & $.77 *$ & $.73 *$ & $.75^{*}$ & $.68 *$ & $.91 *$ & $.88 *$ & $.92 *$ & $.87^{*}$ & $.82 *$ & $(.92)$ \\
\hline 11. roleWFC & 18.21 & 8.55 & $.46^{*}$ & $.33 *$ & $.44^{*}$ & $.42 *$ & $.41^{*}$ & $.25^{*}$ & $.39 *$ & $.38 *$ & $.46^{*}$ & $.40 *$ \\
\hline 12. roleFWC & 16.15 & 8.48 & $.35^{*}$ & $.28 *$ & $.36^{*}$ & $.41 *$ & $.38 *$ & $.27 *$ & $.38 *$ & $.39 *$ & $.39 *$ & $.40 *$ \\
\hline 13. Disengage & 2.26 & .70 & $.16^{*}$ & .06 & .10 & .10 & $.14^{*}$ & -.01 & .05 & .07 & .12 & .07 \\
\hline 14. Reengage & 3.80 & .70 & -.01 & -.02 & .08 & -.02 & .02 & -.05 & .05 & -.08 & .01 & -.01 \\
\hline 15. PSI & 6.50 & 3.30 & $.20 *$ & $.18 *$ & $.27^{*}$ & $.27 *$ & $.19 *$ & $.22 *$ & $.21 *$ & $.25^{*}$ & $.26^{*}$ & $.24 *$ \\
\hline 16. NA & 27.18 & 8.12 & $.15^{*}$ & $.21 *$ & $.14^{*}$ & $.15^{*}$ & $.17 *$ & $.19 *$ & $.19 *$ & $.22 *$ & $.18^{*}$ & $.22 *$ \\
\hline 17. PA & 36.07 & 7.83 & $-.14 *$ & $-.16^{*}$ & $-.16^{*}$ & $-.21 *$ & $-.15 *$ & $-.18 *$ & $-.16^{*}$ & $-.20 *$ & $-.19 *$ & $-.19 *$ \\
\hline 18. Job Sat. & 15.32 & 4.82 & $-.13 *$ & -.07 & $-.16^{*}$ & $-.16^{*}$ & -.07 & -.05 & $-.13 *$ & $-.15 *$ & $-.15^{*}$ & -.11 \\
\hline 19. Turnover Int. & 3.84 & 1.91 & .11 & .01 & $.13 *$ & .08 & .07 & -.03 & .10 & .10 & .09 & .07 \\
\hline
\end{tabular}


Table 1 Cont.

\begin{tabular}{lccccccccc}
\hline & 11. & 12. & 13. & 14. & 15. & 16. & 17. & 18. & 19. \\
\hline 11. roleWFC & $(.93)$ & & & & & & & & \\
12. roleFWC & $.56^{*}$ & $(.89)$ & & & & & & & \\
13. Disengage & .05 & $.16^{*}$ & $(.53)$ & & & & & & \\
14. Reengage & -.03 & $-.18^{*}$ & $-.18^{*}$ & $(.85)$ & & & & & \\
15. PSI & $.31^{*}$ & $.14^{*}$ & -.07 & -.04 & $(--)$ & & & & \\
16. NA & $.23^{*}$ & $.19^{*}$ & .07 & -.05 & $.34^{*}$ & $(.84)$ & & & \\
17. PA & $-.23^{*}$ & $-.19^{*}$ & $-.22^{*}$ & $.13^{*}$ & $-.18^{*}$ & $-.39^{*}$ & $(.89)$ & & \\
18. Job Sat. & $-.48^{*}$ & $-.30^{*}$ & .01 & .10 & $-.26^{*}$ & $-.17^{*}$ & $.16^{*}$ & $(.89)$ & \\
19. Turnover Int. & $.45^{*}$ & $.29^{*}$ & -.04 & -.02 & $.21^{*}$ & .10 & -.10 & $-.63^{*}$ & $(.85)$ \\
\hline
\end{tabular}

Note. NA = Negative Affect, PA = Positive Affect, Job Sat. = Job Satisfaction, Turnover Int. $=$ Turnover Intentions, Disengage $=$ Disengagement Coping Strategy, Reengage $=$ Reengagement Coping Strategy, W-GNW $=$ Work

Conflicting with Global Nonwork, GNW-W = Global Nonwork Conflicting with Work, roleWFC $=$ Pre-established Work-Family Measure, roleFWC = Pre-established Family Work Conflict Measure, SD = Standard Deviation, Diagonal $(* *)$ values represent reliability estimates $(\alpha)$.

${ }^{*}$ Correlation is significant at the 0.05 level (2-tailed) 


\section{Tests of Hypotheses}

Checking Assumptions. The data were checked for normality, linearity, homoscedasticity, and multicollinearity. With the exception of job satisfaction, all outcome variables were normally distributed. After applying a reflect and logarithm transformation (Tabachnick \& Fidell, 2001) to the job satisfaction variable, all tests of hypotheses were unchanged except for Hypothesis 4a, in which partial support was obtained only after the inclusion of transformed job satisfaction. For this reason, transformed values of job satisfaction will be used in place of non-transformed job satisfaction for the remainder of this paper's analyses. No violations of linearity, or homoscedasticity were found. The high degree of intercorrelation present between all specific measures of personal project conflict may lead to a lower likelihood of discovering unique predictors within subsequent regression analyses (i.e., Hypotheses 2 and 3). This having been acknowledged, the level of multicollinearity present between specific measures of inter-goal conflict is acceptable, as the variance inflation factors (VIF) obtained in this study's regression analyses are all below 4 (Tabachnik \& Fidell, 2001).

Mahalanobis distances were calculated in order to identify multivariate outliers. Four significant multivariate outliers were found $\left(\chi^{2}>26.13, p<.0001\right)$, however, no significant differences were observed following their deletion. As a result, all multivariate outliers were retained and the $\mathrm{N}=229$ was used for the purpose of this study's analyses.

Hypothesis 1. Hypothesis 1a proposed that W-GNW would significantly predict decreased well-being. Similarly, Hypothesis 2a proposed that GNW-W would significantly predict decreased well-being. As can be seen from the bivariate correlations (see Table 1), 
W-GNW significantly predicts decreased positive affect, greater negative affect, and number of physical symptoms. However, neither job satisfaction nor turnover intentions are significantly related to GNW-W. Similarly, GNW-W is significantly correlated to all outcomes of interest, with the exception for turnover intentions. As a result both Hypothesis $1 \mathrm{a}$ and $1 \mathrm{~b}$ are partially supported.

Hypothesis 2. Hypothesis 2 a was concerned with the unique relationship between specific types of work-nonwork goal conflicts. Specifically, Hypothesis 2a proposed that greater work-nonwork conflict would significantly predict lower levels of well-being. Similarly, Hypothesis $2 \mathrm{~b}$ proposed that specific nonwork-work conflicts would predict lower levels of well-being. In order to better understand the unique predictors present within sets of work-nonwork and nonwork-work specific goal conflicts, separate hierarchical regressions were run, in which specific work-nonwork or nonwork-work goal conflicts were regressed onto outcomes of interest (see Table 2). Despite the relatively high intercorrelations among specific measures of conflict, moderate success was achieved in the identification of specific inter-goal conflicts as significant unique contributors to participant well-being. As a set, specific types of work-nonwork conflict (work-family, work-social, work-academic, and work-self-care) accounted for significant variance in reported physical symptoms $(F(4,224)=5.83, p<.05)$, positive affect $(F(4,224)=2.78$, $p<.05)$, and negative affect $(F(4,224)=2.52, p<.05)$. Work-self-care conflict contributed unique variance when specific work-nonwork conflicts were regressed onto physical symptoms $(\beta=-.21, t(5,224)=2.10, p<.05)$ or positive affect $(\beta=.21, t(5,224)=-2.03$, $p<.05)$. Similarly, work-social conflict accounted for unique variance in participant's 
reported physical symptoms $(\beta=.26,(5,224)=2.17, p<.05)$. Additionally, workacademic conflict accounted for unique variance in participant negative affect. As a result, a hypothesis 2 a was partially supported. 
Table 2

Hierarchical Regression of Physical Symptoms (PSI), Positive Affect, Negative Affect, Transformed Job Satisfaction, and Turnover Intentions on Specific Work-Nonwork Conflicts

\begin{tabular}{|c|c|c|c|c|c|}
\hline & $\begin{array}{c}\text { Physical } \\
\text { Symptoms } \\
\end{array}$ & $\begin{array}{c}\text { Negative } \\
\text { Affect }\end{array}$ & $\begin{array}{c}\text { Positive } \\
\text { Affect }\end{array}$ & $\begin{array}{c}(\mathrm{t}) \mathrm{Job} \\
\text { Satisfaction }\end{array}$ & $\begin{array}{c}\text { Turnover } \\
\text { Intentions } \\
\end{array}$ \\
\hline Variable Entered: & $\beta$ & $\beta$ & $\beta$ & $\beta$ & $\beta$ \\
\hline \multicolumn{6}{|l|}{ Conflict: } \\
\hline Work-Family & -.14 & .03 & .06 & .06 & .08 \\
\hline Work-Social & $.26^{*}$ & -.04 & -.03 & -.11 & -.19 \\
\hline Work-Academic & -.05 & $.19 *$ & -.04 & .06 & .19 \\
\hline Work-Self-Care & $.21 *$ & .03 & $-.21 *$ & .14 & .01 \\
\hline$F(d f)$ & $5.83(4,224) *$ & $2.52(4,224)^{*}$ & $2.78(4,224) *$ & $1.77(4,224)$ & $1.98(4,224)$ \\
\hline$R^{2}$ & $.09 *$ & $.04 *$ & $.05 *$ & .03 & .03 \\
\hline
\end{tabular}

Note: $* p<.05$ 
Similar regression analyses of specific types of nonwork-work conflict (family-work, social-work, academic-work, and self-care-work) also accounted for significant amounts of variance in reported physical symptoms $(F(4,224)=4.02, p$ $<.05)$, positive affect $(F(4,224)=2.51, p<.05)$, negative affect $(F(4,224)=3.11, p$ $<.05)$, and turnover intentions $(F(4,224)=2.40, p<.05)$. However, only one of these regressions yielded any significant unique contributor. In this single case, academic-work conflict accounted for unique variance in turnover intentions $(\beta=$ $.26, t(4,225)=-2.54, p<.05)$, such that greater academic-work conflict was associated with reduced turnover intentions. Despite this last counterintuitive finding, hypothesis $2 \mathrm{~b}$ was partially supported. 
Table 3

Hierarchical Regression of Physical Symptoms (PSI), Positive Affect, Negative Affect, Transformed Job Satisfaction, and Turnover Intentions on Specific Nonwork-Work Conflicts

\begin{tabular}{|c|c|c|c|c|c|}
\hline & $\begin{array}{l}\text { Physical } \\
\text { Symptoms }\end{array}$ & $\begin{array}{c}\text { Negative } \\
\text { Affect }\end{array}$ & $\begin{array}{c}\text { Positive } \\
\text { Affect }\end{array}$ & $\begin{array}{c}(\mathrm{t}) \mathrm{J} \text { ob } \\
\text { Satisfaction }\end{array}$ & $\begin{array}{l}\text { Turnover } \\
\text { Intentions }\end{array}$ \\
\hline Variable Entered: & $\beta$ & $\beta$ & $\beta$ & $\beta$ & $\beta$ \\
\hline Conflict: & & & & & \\
\hline Family-Work & -.05 & -.03 & .02 & -.02 & .02 \\
\hline Social-Work & .09 & .06 & -.08 & -.15 & .17 \\
\hline Academic-Work & -.05 & .05 & .00 & .10 & $-.26^{*}$ \\
\hline Self-Care-Work & .19 & .16 & -.16 & .20 & .14 \\
\hline$F(d f)$ & $4.02(4,224)^{*}$ & $3.11(4,224)^{*}$ & $2.51(4,224)^{*}$ & $1.94(4,224)$ & $2.40(4,224)^{*}$ \\
\hline$R^{2}$ & $.07^{*}$ & $.05^{*}$ & $.04 *$ & .03 & $.04 *$ \\
\hline
\end{tabular}

Note: $* p<.05$ 
Hypothesis 3. Hypothesis 3a proposed that specific work-nonwork conflicts would predict participant well-being beyond an already established measure of WFC. Similarly, hypothesis $3 b$ proposed that specific nonwork-work conflicts would predict participant well-being beyond a previously established measure of FWC. In order to test hypotheses $3 \mathrm{a}$ and $3 \mathrm{~b}$, separate regressions were run in which an established measure of WFC or FWC were entered in the first step and specific measures of work-nonwork or nonwork-work conflicts were entered in the second step.

For both hypothesis $3 \mathrm{a}$ and $3 \mathrm{~b}$, significant incremental variance beyond previously established WFC and FWC measures was achieved only for the physical symptoms outcome measure. To test hypothesis $3 \mathrm{a}$, the established measure of WFC was controlled for in step one and specific measures of work-nonwork conflict were regressed onto physical symptoms in step two. For this regression analysis, an additional $4 \%$ variance in physical symptoms was accounted for through the inclusion of specific work-nonwork conflicts in step two $(F(5,223)=$ $7.22, p<.05)$. Interestingly, as was found in hypothesis 2 , work-social conflict accounted for unique variance in the prediction of physical symptoms $(\beta=.23, t$ $(5,224)=1.95, p<.05)($ see Table 9$)$. Within a separate regression, a 5\% increase in explained variance for physical symptoms was achieved after controlling for FWC in step one of the regression and including specific nonwork-work conflicts in step two $(F(5,223)=3.34, p<.05)$. However, no unique contributors of variance were found in this second regression. For all other outcomes examined, unique measures of work-nonwork and nonwork-work failed to significantly predict 
beyond established measures of WFC and FWC. Taken as a set, these findings partially support both hypotheses $3 a$ and $3 b$. 
Table 4

Hierarchical Regression of Physical Symptoms (PSI) on Specific Work-Nonwork Conflicts, Having Controlled for a Pre-existing Role-Based Measure of WorkFamily Conflict

\begin{tabular}{lccccc}
\hline Variable & $\beta$ & $\mathrm{R}^{2}$ & $\operatorname{Adj~R}^{2}$ & $\Delta \mathrm{R}^{2}$ & $\mathrm{~F} \Delta$ \\
\hline Block 1: & & .10 & .09 & .10 & $24.08^{*}$ \\
roleWFC & $.31^{*}$ & & & & \\
Block 2: & & .14 & .12 & .04 & $2.82^{*}$ \\
Work-Family & -.21 & & & & \\
Work-Social & $.23^{*}$ & & & & \\
Work-Academic & -.03 & & & & \\
Work-Self-Care & .18 & & & & \\
\hline
\end{tabular}

Note. $\mathrm{N}=229$, Overall $\underline{R}=.37, \underline{F}(5,223)=7.22, p<.05$.

$* p<.05$ 
Hypothesis 4. Hypothesis 4a examined whether individual's likelihood of using goal disengagement and goal reengagement coping strategies serve as effective moderators of W-GNW conflict and participant well-being. Similarly, hypothesis $4 \mathrm{~b}$ assessed the effectiveness of dispositional self-regulatory coping in relationship to GNW-W conflict. In order to assess hypothesis 4a, two regression analyses were run. In order to test whether disengagement coping style was an effective moderator, W-GNW was entered in the first step of the regression equation, followed by disengagement coping strategy in step two of the regression equation, and finally the interaction term of W-GNWxDisengagement in the third step. Similarly, when testing reengagement coping style as an effective moderator, W-GNW was entered in the first step of the regression equation, followed by reengagement coping strategy in step two of the regression equation, and finally the interaction term of W-GNWxReengagement in the third step. Following this procedure, only the interaction of W-GNWxDisengagement was found to significantly predict negative affect $(F(3,225)=4.11, p<.05)($ see Table 5$)$. Graphic representation of the W-GNWxDisengagement interaction suggests that participants higher in disengagement coping and experiencing lower W-GNW conflict reported more negative affect than participants that were lower in disengagement coping strategy and experiencing lower W-GNW conflict (see Figure 1). As such hypothesis 4a was not supported. 
Table 5

Hierarchical Regression of Negative Affect on Disengagement Coping Interacting with Work Conflicting with Global Nonwork, Having Controlled for Work Conflicting with Global Nonwork and Reengagement Coping

\begin{tabular}{lccccc}
\hline Variable & $\beta$ & $\mathrm{R}^{2}$ & $\operatorname{Adj~R}^{2}$ & $\Delta \mathrm{R}^{2}$ & $\mathrm{~F} \Delta$ \\
\hline $\begin{array}{l}\text { Block 1: } \\
\text { W-GNW }\end{array}$ & $.18^{*}$ & .03 & .03 & .03 & $7.87^{*}$ \\
$\begin{array}{l}\text { Block 2: } \\
\quad \text { Disengagement Coping (DC) }\end{array}$ & .05 & & & & \\
\\
$\begin{array}{l}\text { Block 3: } \\
\quad \text { W-GNW x DC }\end{array}$ & & .04 & .03 & .00 & .59 \\
& $-.13^{*}$ & & & & \\
\end{tabular}

Note. $\mathrm{N}=229$, Overall $\underline{R}=.23, \underline{F}(3,225)=4.11, p<.05$.

$* p<.05$ 
A similar procedure was used to assess hypothesis $4 \mathrm{~b}$ (GNW-W was substituted for W-GNW in the above described regression analyses), such that two regression analyses were run testing whether individual predispositions to use disengagement or reengagement coping strategies effectively moderated the relationship between GNW-W and well-being. To test disengagement coping as a potential moderator, GNW-W was entered in the first step of the regression equation, followed by disengagement coping strategy in second step, and finally the interaction term of GNW-WxDisengagement in the third step of the regression. Similarly, when testing reengagement coping style as an effective moderator, GNW-W was entered in the first step of the regression equation, followed by reengagement coping strategy in step two, and finally the interaction term of WGNWxReengagement in the third step. Following this procedure, only GNWWxReengagement was found to significantly predict (transformed) job satisfaction $(F(3,225)=3.87, p<.05)($ see Table 6$)$. Graphic representation of the reengagement coping strategy and GNW-W interaction suggests that individuals higher in reengagement and reporting lower GNW-W conflict were more satisfied with their jobs than participants that were lower in reengagement coping strategy and reporting lower GNW-W conflict (see Figure 2). As such hypothesis $4 \mathrm{~b}$ was partially supported. 
Table 6

Hierarchical Regression of Transformed Job Satisfaction on Reengagement Coping Interacting with Global Nonwork Conflicting with Work, Having Controlled for Work Conflicting with Global Nonwork and Reengagement Coping

\begin{tabular}{|c|c|c|c|c|c|}
\hline Variable & $\beta$ & $\mathrm{R}^{2}$ & $\operatorname{Adj~} R^{2}$ & $\Delta \mathrm{R}^{2}$ & $\mathrm{~F} \Delta$ \\
\hline $\begin{array}{l}\text { Block 1: } \\
\text { GNW-W }\end{array}$ & .11 & .01 & .01 & .01 & 2.95 \\
\hline $\begin{array}{l}\text { Block 2: } \\
\quad \text { Reengagement Coping ( } \mathrm{RC})\end{array}$ & -.12 & .03 & .03 & .01 & 3.22 \\
\hline $\begin{array}{l}\text { Block 3: } \\
\qquad \text { GNW-W x RC }\end{array}$ & $.15^{*}$ & .05 & .04 & .02 & $5.30 *$ \\
\hline
\end{tabular}

Note. $\mathrm{N}=229$, Overall $\underline{R}=.22, \underline{F}(3,225)=3.87, p<.05$.

$* p<.05$ 
Hypothesis 5. Hypothesis 5a assessed whether predispositions to use disengagement or reengagement coping moderated the relationship between worksocial conflict and well-being. Similarly, hypothesis $5 \mathrm{~b}$ examined whether likelihood of using disengagement or reengagement coping moderated the relationship between social-work conflict and well-being. The same regression format used to assess hypothesis 4 was employed here, so that work-social conflict was entered into the first step of the regression equation, followed by disengagement or reengagement coping in the second step, and then the interaction of work-socialxDisengagement or work-socialxReengagement in the third step of the regression. Similarly, to test hypothesis $5 \mathrm{~b}$, social-work conflict was entered into the first step of the regression equation, followed by either disengagement or reengagement coping in step two, and the interaction of socialworkxDisengagement or social-workxReengagement in step three of the regression. All regressions testing hypothesis $5 \mathrm{a}$ and $5 \mathrm{~b}$ were non-significant. As a result, hypotheses $5 \mathrm{a}$ and $5 \mathrm{~b}$ were not supported.

Hypothesis 6. Hypothesis 6a attempted to assess whether predispositions to use disengagement and reengagement coping moderated the relationship between work-academic conflict and well-being. Similarly, hypothesis $6 \mathrm{~b}$ examined whether dispositional disengagement and reengagement coping moderated the relationship between academic-work conflict and well-being. The same regression format used to assess hypothesis 5 was employed here, except that values of workacademic conflict and academic-work conflict were substituted for those of worksocial and social-work respectively. All regressions testing hypothesis 6a were 
non-significant. However, when testing hypothesis $6 \mathrm{~b}$, the interaction of academicworkxReengagement accounted for a $2 \%$ significant increase in explained variance for job satisfaction $(F(3,225)=2.98, p<.05)($ see Table 7$)$. Once the interaction predicting job satisfaction was examined graphically, reengagement coping strategy and academic-work conflict appeared to interact such that participants higher in reengagement and reporting lower academic-work conflict reported more job satisfaction than participants lower in reengagement coping strategy and reporting lower academic work conflict (see Figure 3 ). As such hypothesis $6 \mathrm{~b}$ was partially supported. 
Table 7

Hierarchical Regression of Job Satisfaction on Reengagement Coping Interacting with Academic-Work Conflict, Having Controlled for Academic-Work Conflict and Reengagement Coping

\begin{tabular}{cccccc}
\hline Variable & $\beta$ & $\mathrm{R}^{2}$ & $\operatorname{Adj~}^{2}$ & $\Delta \mathrm{R}^{2}$ & $\mathrm{~F} \Delta$ \\
\hline Block 1: & & .00 & .00 & .00 & .60
\end{tabular}
Academic-Work Conflict (AWC) $\quad .04$

Block 2:

Reengagement Coping (RC)

$\begin{array}{llll}.02 & .01 \quad .01 \quad 2.18\end{array}$

Block 3:

$\begin{array}{llll}.15 * \quad .04 & .03 \quad .02\end{array}$

4.33*

AWC $x$ RC

Note. $\mathrm{N}=229$, Overall $\underline{R}=.20, \underline{F}(3,225)=2.98, p<.05$.

$* p<.05$ 


\section{Discussion}

As expected, specific work-nonwork and nonwork-work conflicts significantly predicted physical and psychological well-being. However, in general, specific work-nonwork and nonwork-work conflicts failed to consistently predict job satisfaction and turnover intentions. Of the conflicts measured, only worksocial conflict significantly correlated with both turnover intentions and job satisfaction, whereas work-self-care and self-care-work conflict only predicted job satisfaction. Although, during the pilot research, goals within the academic domain were more frequently mentioned than social and self-care goals, the work-social and work-self-care conflicts appear to be of particular significance to the sample studied. Despite the most frequently mentioned goals within the pilot study being related to academics, this study's findings further suggest that goal frequency and goal saliency are not comparable.

The PPA instruction of "...give us more the everyday activities or concerns that characterize your life at present" (see Appendix A) may have led participants to focus on goals ranging from short-term to long term-goals as well as conflicts between goals with various time constraints. The potential range of duration for conflicting goals inherent in this study's PPA may be less likely to predict more distal outcome measures such as job satisfaction and turnover intentions (these scales used wording that tended to focus on non-state job attitudes, such as "in general I don’t like my job" or "I often think about quitting this organization."). A 
focus on short-term goal conflicts may also explain why goal conflict only accounted for small amounts of variance in positive affect (5\%), negative affect (4\%), and physical symptoms (9\%) (see Tables $2 \& 3$ ). Although the PANAS and PSI represented more state/proximal measures of well-being, their prompts still focused on outcomes potentially less susceptible to short term goal conflict (PANAS prompt assessed mood "during the past week" and the PSI assessed symptoms occurring "during the past 30 days"). Had the PPA requested only long term goals (potentially equivalent to self-regulatory higher order "be" goals) from participants, intergoal conflicts may have been of longer duration and more likely to account for additional variance in outcomes of interest. Although this study's results do not explicitly explore either long-term or short-term goal conflict, they do underscore the importance of future research examining the relationship of goal conflict and outcome measures using the same span of time. For example, researchers may request goal conflicts present during the past two weeks and likewise assess participant well-being for the period associated with the previous two weeks. Alternatively, using a diary method, researchers may be able to more accurately capture the relationship between goal conflict and the development of physical symptoms, job attitudes, and affect.

The ability of researchers to focus on either short-term or long-term goals when assessing intergoal conflict highlights the advantages of conceptualizing WLC from a goal based, self-regulatory perspective. Traditional role based conceptualizations of WLC are limited in their perspective and do not capture the dynamic information contained within individual goals. Future research into WLC 
may benefit from assessing the relationship between conflicting long-term goals as well as a combination of conflicting long-term and short-term goals and well-being.

When examined through regression analysis, nonwork-work goal conflict accounted for significant variance in turnover intentions. Within this regression (see Table 3), academic-work conflict accounted for unique variance in turnover intentions and indicates that individuals experiencing greater academic-work conflict have lower turnover intentions. Upon further consideration, this unexpected finding may be explained through the low human capital sample used for this study's research. It may be the case that as individuals experience their academic goals conflicting with their work goals, intentions to turnover are decreased due to the individual's low likelihood of finding alternative employment that differs substantially from their current employment. For the current sample, seeking alternative employment may be viewed as being a further distraction from academic goals and therefore turnover intentions are reduced.

The relationship between academic-work conflict and job attitudes was again seen in the significant incremental variance accounted for in job satisfaction by the interaction of academic-work conflict and goal reengagement coping strategy (Hypothesis 6; see Table 7). Once graphically represented, this interaction suggests that participants high in reengagement and low in academic-work conflict reported greater job satisfaction than participants low in reengagement coping strategy and low in academic-work conflict (see Figure 3). This relationship may be due to a greater range of alternative goals available to individuals experiencing lower levels of goal conflict. These additional alternative goals available to individuals 
experiencing low goal conflict may enable reengagement coping strategies to be used more effectively in order to moderate the relationship between academic-work conflict and well-being.

With the above exceptions, both disengagement and reengagement coping strategies were ineffective moderators of the relationship between specific goal conflicts and participant well-being. Although this may again be reflective of the unique issues surrounding short-term goal conflict, disengagement and reengagement coping may be generally ineffective strategies when used within a work context. It may be that the constraints of workplace do not allow for disengagement and reengagement coping to readily be used. This constraint's impact on individual ability to employ disengagement and reengagement coping within the workplace may explain the current study's predominant lack of support for the moderation hypotheses $4 \mathrm{~b}$ through $6 \mathrm{a}$. The current study's results are therefore comparable to McKee, et al.'s (2006) findings regarding disengagement and reengagement coping as potential moderators of goal progress and burnout.

\section{Implications}

The results of this study support the goal based conceptualization of WLC as suggested by Edwards (1998). Additionally, this study supports the use of PPA as a tool by which a goal based understanding of WLC can be achieved. Despite previous researchers' problems utilizing the cross impact matrix portion of the PPA, this study's on-line collection methodology allowed for efficient collection of participant ratings of intergoal conflict. Future research into goal based conceptualizations of WLC conflict may also benefit from using a computerized 
PPA cross-impact matrix. Furthermore, future research into intergoal conflict, as measured by the PPA, should examine the difference between short-term goals (as measured in the study) vs. long-term personal projects/goals.

The results of this study clearly indicate that the traditional conceptualization of WLC, which is comprised of primarily WFC and FWC, is inadequate and that the consideration of goals within other life domains such as academics, social life, and self-care is relevant. This study's results suggest that for the university sample surveyed, work-social conflict is of particular importance when understanding WLC's relationship to physical well-being. Additionally, consideration of work-self-care conflict is recommended when attempting to use WLC to predict employee positive affect and physical symptoms. Furthermore, work-academic conflict was found to be important in the prediction of employee negative affect. Additional research is required to test whether these relationships exist within other professions and whether specific types of conflict are more relevant during certain periods within one's life. For example, this study's amount of variance in well-being accounted for by work-social conflict may not be replicated within a non-university setting.

This study's finding that academic-work conflict is negatively correlated to turnover intentions suggests that the employee context is an important consideration when understanding how intergoal conflict predicts job related attitudes. Similarly, employment context seems to be important when considering the potential utility of self-regulatory coping strategies. It seems that within the current sample and the nursing sample used by McKee and colleagues (2006), disengagement and 
reengagement coping styles are either ineffective or counterproductive. As these repeated finding are counter to Wrosch and colleagues original research (2003), additional research is needed in order to explore potential work contexts conducive to disengagement and reengagement coping.

It may be useful for organizations to assess the fit between organizational goals and current or prospective employee goals. Through the identification potential goal conflicts, interventions and selection decisions could be put in place for current as well as prospective employees. In addition to assessing and discussing potential goal conflict (conflict matrix including organizational goals on the vertical axis and individual goals on the horizontal axis), realistic job previews could be used to assist applicants' assessment of potential goal conflicts.

\section{Limitations}

Several limitations exist for this research. The data collected during study is cross sectional in nature and any progression of disengagement to reengagement coping, or alternatively affective responses to physical and organizational wellbeing, is not available. Additionally, the assessment of disengagement and reengagement coping asked participants what their style or predisposition for coping was and did not actually assess the coping strategies used to deal with particular goal conflicts. It may be that constraints unique to each goal domain restrict or facilitate certain types of goal directed coping and neither this nor actual coping behavior is captured in the current study. Furthermore, the level of abstraction present within the personal project analysis may allow for goals that span both "be" and "do" goals. Although the PPA clearly asks for goals that are 
short-term in nature, the span of goals present within the data may complicate interpretations of goal conflict. Lastly, the manner in which participant goals was collected only allows for three goals per domain. As each domain may have more or less goals than the three required during the survey, the issue of goal importance is raised. It may be that differential weightings of specific goal conflicts based on participant ratings of importance are implicitly present within the data. Although all participants in this study were employed it is likely that varying levels of work goal importance were present within the data. As only $8 \%$ of the pilot study's personal projects were work related, it is possible that for employed undergraduates, work projects are not as important as other nonwork related projects.

Unfortunately, the ability to disentangling differences among intergoal conflict importance is unavailable using the current methodology.

Additionally, this study's findings are limited due to the use of a mostly part time employed university student sample instead of a full-time employed adult sample. This limitation stems not only from the potential differences inherent between part-time and full-time employees but also is the result of the differences associated with a younger university student sample, as compared to their employed non-university adult counterparts. As mentioned above, only $8 \%$ of the goals elicited during the pilot study were work related. As this frequency may differ substantially for either full-time employees or employed adults not attending university, this study's findings may only generalize to a similarly employed university sample. 
A further limitation of this research stems from the 80 regressions run in order to test this study's hypotheses. Assuming a $p<.05$ level of probability, 4 spurious findings can be expected to result from this study's analyses. As this study's tests of hypotheses yielded more than 4 significant findings, the pattern of results found in this research can be interpreted as being consistent with theoretical expectations. It is important to note that the number of regressions used to test this study's hypotheses does not result from an exploratory type approach to data analysis, but instead represents an approach grounded in theory and the result of a methodology yielding rich information.

\section{Future Research}

Future research examining goal conflict across domains of individuals' lives would benefit from the assessment of goal importance for each goal elicited. Using weighted conflict scores capturing ratings of importance for each goal elicited may improve the ability of future research to predict participant's well-being and job attitudes. Future researchers will need to develop a method which effectively differentiates goal importance among elicited personal projects. As each project elicited during a PPA is somehow salient to the individual at the moment of elicitation, differentiating among these projects may require a forced ranking of project importance or a consideration of multiple factors leading to individual perceptions of importance, such as duration and complexity.

Additionally, future research examining goal based conceptualizations of WLC would benefit from assessing goal conflicts and outcomes measures using comparable spans of time. Although this method was not used for the current 
research, this study does highlight the ability for current versions of the PPA and cross impact matrix to effectively predict employee well-being despite the short or long duration of potential goal conflicts. 


\section{Conclusion}

This study supports a goal based conceptualization of WLC as suggested by Edwards (1998) and further suggests that domain conflicts beyond the traditional work-family conflict are relevant when attempting to understand employee wellbeing. The results of this study suggest that the family, academic, social, and selfcare domains each are important predictors of employee psychological and physical well-being, as well as job attitudes such as job satisfaction and turnover intentions. Based on these findings it is suggested that employers attempt to understand the specific conflicts between employee work and nonwork goals when implementing work-life friendly policies.

By assessing WLC in terms of conflicting goals, a targeted approach to reducing employee stress is achievable. Through the regular assessment of employee intergoal conflict, employers will be able to implement specific interventions aimed at reducing relevant goal conflicts. Although traditional workfamily friendly initiatives may be effective at reducing work-family conflict, alternative approaches are likely necessary to facilitate lower levels of work-social, work-academic, or work-self-care conflicts. For example, workplaces that provided health oriented options such as reduced calorie snacks and on-sight health care may succeed in reducing employee perceptions of work-self-care goal conflicts. 
Similarly, workplaces may attempt to reduce work-academic conflict by offering flex-time for employees currently enrolled in classes. 


\section{FIGURE 1}

Interaction of disengagement coping and W-GNW predicting negative affect

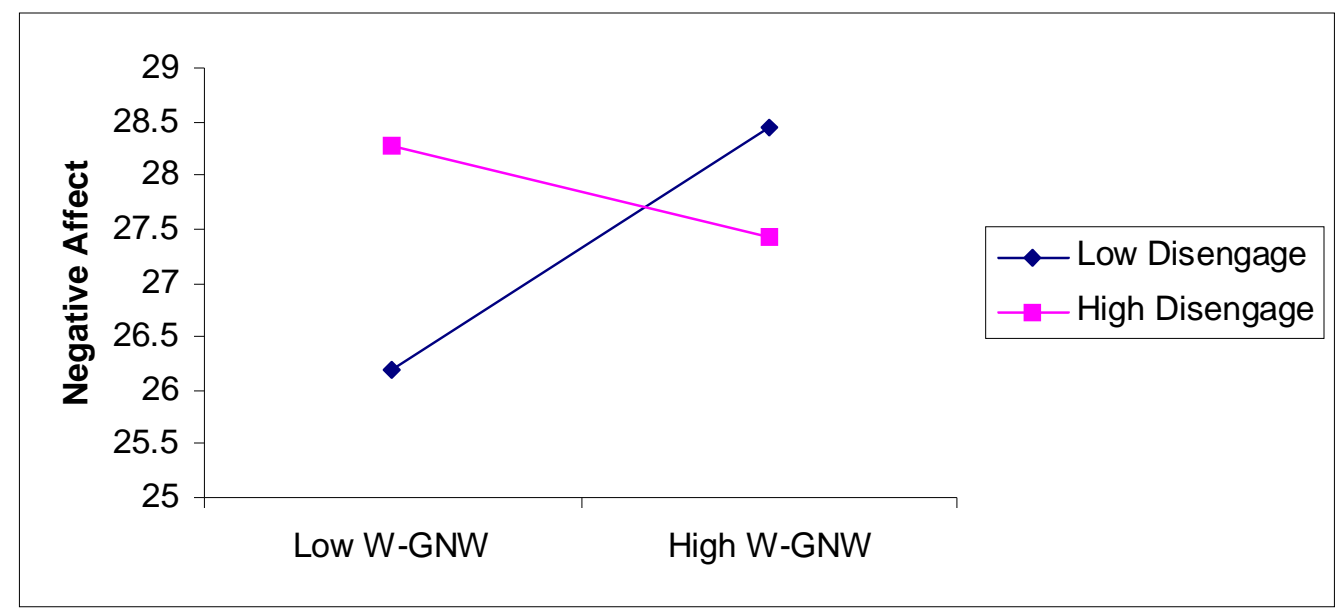




\section{FIGURE 2}

Interaction of reengagement coping and GNW-W predicting transformed job satisfaction (higher values on job satisfaction indicate reduced job satisfaction)

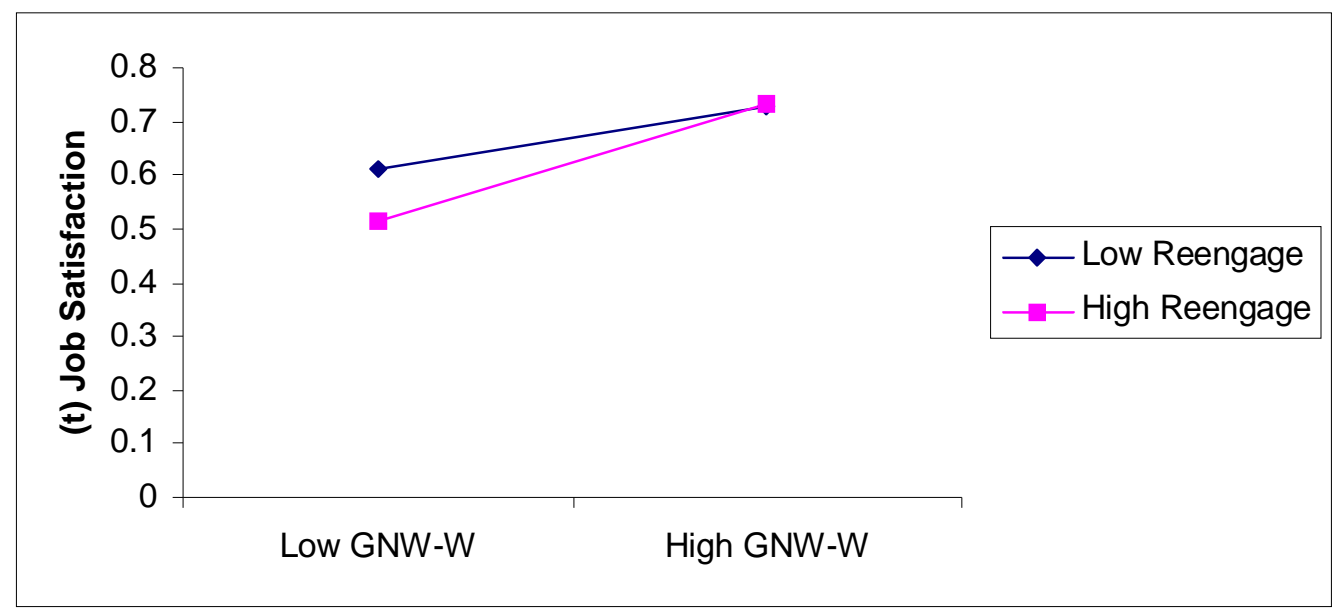




\section{FIGURE 3}

Interaction of reengagement coping and AWC predicting job satisfaction (higher values on job satisfaction indicate reduced job satisfaction)

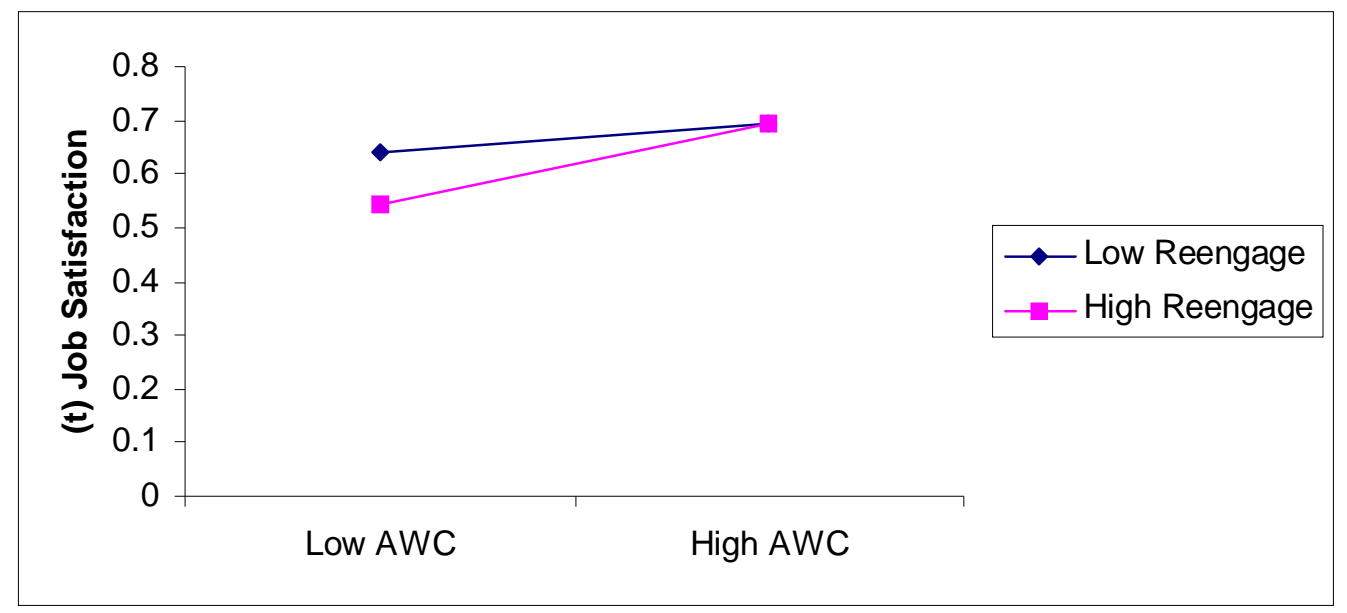




\title{
APPENDIX A
}

We are interested in studying the kinds of activities and concerns that people have over the course of their lives. We call these personal projects. All of us have a number of personal projects at any given time that we think about, plan for, carry out and sometimes (though not always) complete.

Some projects may be focused on achievement ("Getting my degree") others on the process ("Enjoying a night out with friends"); they may be things we choose to do or things we have to do; they may be things we are working towards or things we are trying to avoid. Projects may be related to any aspect of your daily life, university, work, home, leisure and community, among others. Please think of projects in this broad way.

\section{Some examples of projects}

\author{
- $\quad$ Pass my psychology course \\ - $\quad$ Cut down on junk food \\ - $\quad$ Play with my cat \\ - $\quad$ Clean my apartment \\ - $\quad$ Try not to make my parents mad \\ - $\quad$ Clarify my religious beliefs \\ - $\quad$ Exercise more often \\ - $\quad$ Go to Europe this summer \\ - $\quad$ Be a better parent \\ - $\quad$ Break off with Robert \\ - $\quad$ Climb the Matterhorn \\ - Understand Suzanne better \\ - $\quad$ Find a part-time job \\ - $\quad$ Stop putting off studying until the last minute
}

We are also interested in finding out what you think and how you feel about these personal projects and activities, how important or stressful they are, and so on.

To start, please take 5 minutes and write down on the following page(s) as many personal projects and activities you can that you are currently engaged in or considering -- remember these need not be formal projects or even important ones -we would prefer you to give us more of the everyday kinds of activities or concerns that characterize your life at present. 
Please take the next 5 minutes to list 3 of your projects for each of the following 5 categories. For each project you list, use the following scale to indicate the project's importance to you:

\section{$\underline{\text { Occupational Personal Projects }}$}

1.

2.

3.

Family Personal Projects

1.

2.

3.

Social Life Personal Projects

1.

2.

3.

$\underline{\text { Academic Personal Projects }}$

1.

2.

3.

$\underline{\text { Self-Care Personal Projects }}$

1.

2.

3. 
Personal Project Conflict:

Please rate the degree to which each of your occupational personal projects are in conflict with your other projects listed above. Use the following scale to indicate the degree of conflict between your personal projects:

$$
\begin{aligned}
& 0=\text { none } \\
& 1=\text { little } \\
& 2=\text { somewhat } \\
& 3=\text { much } \\
& 4=\text { a great deal }
\end{aligned}
$$

1. How much does occupational project 1 conflict with family project 1 ?

2. How much does occupational project 2 conflict with family project 1 ?

3. How much does occupational project 3 conflict with family project 1 ?

4. How much does occupational project 1 conflict with family project 2 ?

5. How much does occupational project 2 conflict with family project 2 ?

6. How much does occupational project 3 conflict with family project 2 ?

7. How much does occupational project 1 conflict with family project 3 ?

8. How much does occupational project 2 conflict with family project 3 ?

9. How much does occupational project 3 conflict with family project 3 ?

10. How much does occupational project 1 conflict with Social project 1 ?

11 . How much does occupational project 2 conflict with Social project 1 ?

12. How much does occupational project 3 conflict with Social project 1 ?

13. How much does occupational project 1 conflict with Social project 2 ?

14. How much does occupational project 2 conflict with Social project 2 ?

15. How much does occupational project 3 conflict with Social project 2 ?

16. How much does occupational project 1 conflict with Social project 3 ?

17. How much does occupational project 2 conflict with Social project 3 ?

18. How much does occupational project 3 conflict with Social project 3 ?

19. How much does occupational project 1 conflict with academic project 1 ?

20. How much does occupational project 2 conflict with academic project 1 ?

21 . How much does occupational project 3 conflict with academic project 1 ?

22 . How much does occupational project 1 conflict with academic project 2 ?

23 . How much does occupational project 2 conflict with academic project 2 ?

24 . How much does occupational project 3 conflict with academic project 2 ?

25 . How much does occupational project 1 conflict with academic project 3 ?

26 . How much does occupational project 2 conflict with academic project 3 ?

27 . How much does occupational project 3 conflict with academic project 3 ?

28 . How much does occupational project 1 conflict with self-care project 1 ?

29 . How much does occupational project 2 conflict with self-care project 1 ?

30 . How much does occupational project 3 conflict with self-care project 1 ?

31 . How much does occupational project 1 conflict with self-care project 2 ?

32 . How much does occupational project 2 conflict with self-care project 2 ?

33 . How much does occupational project 3 conflict with self-care project 2 ? 
34. How much does occupational project 1 conflict with self-care project 3 ? 35 . How much does occupational project 2 conflict with self-care project 3 ? 36. How much does occupational project 3 conflict with self-care project 3 ? 37. How much does family project 1 conflict with occupational project 1 ? 38 . How much does family project 2 conflict with occupational project 1 ? 39 . How much does family project 3 conflict with occupational project 1 ? 40 . How much does family project 1 conflict with occupational project 2 ? 41 . How much does family project 2 conflict with occupational project 2 ? 42 . How much does family project 3 conflict with occupational project 2 ? 43. How much does family project 1 conflict with occupational project 3 ? 44. How much does family project 2 conflict with occupational project 3 ? 45 . How much does family project 3 conflict with occupational project 3 ? 46. How much does social project 1 conflict with occupational project 1 ? 47. How much does social project 2 conflict with occupational project 1 ? 48 . How much does social project 3 conflict with occupational project 1 ? 49 . How much does social project 1 conflict with occupational project 2 ? 50 . How much does social project 2 conflict with occupational project 2 ? 51 . How much does social project 3 conflict with occupational project 2 ? 52 . How much does social project 1 conflict with occupational project 3 ? 53. How much does social project 2 conflict with occupational project 3 ? 54 . How much does social project 3 conflict with occupational project 3 ? 55 . How much does academic project 1 conflict with occupational project 1 ? 56 . How much does academic project 2 conflict with occupational project 1 ? 57. How much does academic project 3 conflict with occupational project 1 ? 58 . How much does academic project 1 conflict with occupational project 2 ? 59 . How much does academic project 2 conflict with occupational project 2 ? 60 . How much does academic project 3 conflict with occupational project 2 ? 61 . How much does academic project 1 conflict with occupational project 3 ? 62 . How much does academic project 2 conflict with occupational project 3 ? 63. How much does academic project 3 conflict with occupational project 3 ? 64. How much does self-care project 1 conflict with occupational project 1 ? 65 . How much does self-care project 2 conflict with occupational project 1 ? 66. How much does self-care project 3 conflict with occupational project 1 ? 67. How much does self-care project 1 conflict with occupational project 2 ? 68 . How much does self-care project 2 conflict with occupational project 2 ? 69. How much does self-care project 3 conflict with occupational project 2 ? 70. How much does self-care project 1 conflict with occupational project 3 ? 71. How much does self-care project 2 conflict with occupational project 3 ? 72. How much does self-care project 3 conflict with occupational project 3 ? 


\section{APPENDIX B}

\section{Work-Family and Family Work Conflict Scale}

Please use the following scale to record your answers

\section{Work-Family Conflict Scale}

$$
\begin{aligned}
& 1=\text { strongly disagree } \\
& 2=\text { moderately disagree } \\
& 3=\text { slightly disagree } \\
& 4=\text { neither disagree nor agree } \\
& 5=\text { slightly agree } \\
& 6=\text { moderately agree } \\
& 7=\text { strongly agree }
\end{aligned}
$$

1. The demands of my work interfere with my home and family life.

2. The amount of time my job takes up makes it difficult to fulfill family responsibilities.

3. Things I want to do at home do not get done because of the demands my job puts on me.

4. My job produces strain that makes it difficult to fulfill family duties.

5. Due to work-related duties, I have to make changes to my plans for family activities.

\section{Family-Work Conflict Scale}

1. The demands of my family or spouse/partner interfere with work-related activities.

2. I have to put off doing things at work because of demands on my time at home.

3. Things I want to do at work don't get done because of the demands of my family or spouse/partner.

4. My home life interferes with my responsibilities at work such as getting to work on time, accomplishing daily tasks, and working overtime.

5. Family-related strain interferes with my ability to perform job-related duties. 


\section{APPENDIX C}

Work-School Conflict Scale:

People who work and go to school sometimes find that their job and school life interfere with each other. Using the following scale, indicate how frequently you experience each situation:

$$
\begin{aligned}
& 1=\text { never } \\
& 2=\text { rarely } \\
& 3=\text { sometimes } \\
& 4=\text { frequently } \\
& 5=\text { very often }
\end{aligned}
$$

1.) Because of my job, I go to school tired.

2.) My job demands and responsibilities interfere with my school work.

3.) I spend less time studying and doing homework because of my job.

4.) My job takes up time that I'd rather spend at school or on school work.

5.) When I'm at school, I spend a lot of time thinking about my job.

\section{School-Work Conflict Scale}

6.) Because of school, I go to my job tired.

7.) School demands and responsibilities interfere with my job.

8.) I spend less time at my job because I need to study and do homework for school.

9.) My school work takes up time that I'd rather spend at my job.

10.) When I'm at school, I spend a lot of time thinking about my job. 


\section{APPENDIX D \\ Goal Disengagement and Goal Reengagement Coping}

This scale consists of several items that measure goal disengagement or goal reengagement preferences. There are no "right" or "wrong" answers, so please answer the prompts to the best of your ability. Use the following scale to record your answers

$$
\begin{aligned}
& 1=\text { almost never true } \\
& 2=\text { usually not true } \\
& 3=\text { occasionally true } \\
& 4=\text { usually true } \\
& 5=\text { almost always true }
\end{aligned}
$$

\section{If I have to stop pursuing an important goal in my life:}

1. It's easy for me to reduce my effort toward the goal.

2. I find it difficult to stop thinking about the goal.

3. I stay committed to the goal for a long time.

4. It's easy for me to stop thinking about the goal and let it go.

5. I think about other new goals to pursue

6. I seek other meaningful goals

7. I convince myself that I have other meaningful goals to pursue.

8. I tell myself that I have a number of other new goals to draw on.

9. I start working on other new goals.

10. I put effort toward other meaningful goals. 


\section{APPENDIX E}

Physical Symptoms Inventory

During the past 30 days did you have any of the following symptoms? If you did have the symptom, did you see a doctor about it?

DURING THE PAST 30 DAYS DID YOU HAVE?

1. An upset stomach or nausea

2. A backache

3. Trouble sleeping

4. A skin rash

5. Shortness of breath

6. Chest pain

7. Headache

8. Fever

9. Acid indigestion or heartburn

10. Eye strain

11. Diarrhea

12. Stomach cramps (Not menstrual)

13. Constipation

14. Heart pounding when not exercising

15. An infection

16. Loss of appetite

17. Dizziness

18. Tiredness or fatigue

$\begin{array}{lll}\text { No I } & \text { Yes I did but } & \text { I did and } \\ \text { didn't } & \text { did not see } & \text { I saw } \\ & \text { doctor } & \text { doctor }\end{array}$

12

12

12

12

12

12

12

12

12

12

12

12

12

12

12

12

12

12

3

3

3

3

3

3

3

3

3

3

3

3

3

3

3

3

3

3

Since the beginning of the academic year, how many:

-Visits have you made to the health center or private physician?

-Days have you been sick?

-Days your activity has been restricted due to illness? 


\section{APPENDIX F}

Positive and Negative Affectivity Scale

This scale consists of a number of words that describe different feelings and emotions. Read each item and then mark the appropriate answer in the bubble next to that word. Indicate what extent you have felt this way during the past week. Use the following scale to record your answers:

$$
\begin{aligned}
& 1=\text { Very slightly or not at all } \\
& 2=\text { A little } \\
& 3=\text { Moderately } \\
& 4=\text { Quite a bit } \\
& 5=\text { Extremely }
\end{aligned}
$$

1. Interested

2. Distressed

3. Excited

4. Upset

5. Strong

6. Guilty

7. Scared

8. Hostile

9. Enthusiastic

10. Proud

11. Irritable

12. Alert

13. Ashamed

14. Inspired

15. Nervous

16. Determined

17. Attentive

18. Jittery

19. Active

20. Afraid 


\section{APPENDIX G}

\section{Job Satisfaction.}

Please indicate the extent to which you agree or disagree with each of the following statements about your job by clicking the appropriate response:

$$
\begin{aligned}
& 1=\text { strongly disagree } \\
& 2=\text { disagree } \\
& 3=\text { slightly disagree } \\
& 4=\text { neither agree nor disagree } \\
& 5=\text { slightly agree } \\
& 6=\text { agree } \\
& 7=\text { strongly agree }
\end{aligned}
$$

1.) All in all I am satisfied with my job.

2.) In general, I don't like my job.

3.) In general, I like working here.

4.) I feel fairly well satisfied with my present job. 


\section{APPENDIX H}

\section{Turnover Intentions}

Please indicate the extent to which you agree or disagree with each of the following statements about your job by clicking the appropriate response:

$$
\begin{aligned}
& 1=\text { strongly disagree } \\
& 2=\text { disagree } \\
& 3=\text { slightly disagree } \\
& 4=\text { neither agree nor disagree } \\
& 5=\text { slightly agree } \\
& 6=\text { agree } \\
& 7=\text { strongly agree }
\end{aligned}
$$

1.) I intend to search for a position with another employer within the next year.

2.) I intend to leave this organization within the next year.

3.) I often think about quitting this organization. 


\section{APPENDIX I}

\section{General Demographics}

1. Age:

2. Sex: $M$ or $F$

3. Race:

4. Class rank:

5. Marital status:

6. Number of children:

7. Type of job:

8. Hours worked each week: 


\section{References}

Anderson, S. E., Coffey, B. S., \& Byerly, R. T. (2002). Formal organizational initiatives and informal workplace practices: Links to work-family conflict and job related outcomes. Journal of Management, 28, 787-810.

Balmforth, K., \& Gardner, D. (2006). Conflict and facilitation between work and family: Realizing the outcomes for organizations. New Zealand Journal of Psychology, 35(2), 69-76.

Barling, J., MacEwen, K. E., Kelloway, E. K., \& Higginbottom, S. F. (1994).

Predictors and outcomes of elder-care-based interrole conflict. Psychology and Aging, 9(3), 391-397.

Barling, J., Rogers, K., \& Kelloway, E. K. (1995). Some effects of teenagers' parttime employment: The quantity and quality of work make the difference. Journal of Organizational Behavior, 16(2), 143-154.

Barnett, R. C. (1999). A new work-life model for the twenty-first century. The Annals of the American Academy, 562, 143-158.

Beck, A. T., Ward, C. H., Mendelsohn, M., Mosck, L, \& Erlaugh, J. (1961). An inventory of measuring depression. Archives of General Psychiatry, 4, 561571.

Bellavia, G. M. \& Frone, M. R. (2005). Work Family Conflict. In Barling, J., Kelloway, K. E. \& Frone, M. R. (Eds.), Handbook of Work Stress (pp. 113148). Thousand Oaks, CA: Sage Publications, Inc. 
Brunstein, J. C. (1993). Personal goals and subjective well-being: A longitudinal study. Journal of Personality and Social Psychology, 65, 1061-1070.

Button, S. B., Mathieu, J. E., \& Zajac, D. M. (1996). Goal orientation in organizational research: A conceptual and empirical foundation. Organizational Behavior and Human Decision Processes, 67(1), 26-48.

Byron, K. (2005). A meta-analytic review of work-family conflict and its antecedents. Journal of Vocational Behavior, 67(2), 169-198.

Cammann, C., Fichman, M., Jenkins, D., \& Klesh, J. (1979). The Michigan organizational assessment questionnaire. Unpublished manuscript, University of Michigan, Ann Arbor.

Campion, M. A., \& Lord, G. (1982). A control systems conceptualization of the goal-setting and changing process. Organizational Behavior \& Human Performance, 30(2), 265-287.

Cantor, N. (1990). From thought to behavior: "Having" and "doing" in the study of personality and cognition. American Psychologist, 45, 745-750.

Carver, C. S., \& Scheier, M. F. (1999). Stress coping, and self-regulatory processes. In Pervin, L. A., \& John, O. P. (Eds.), Handbook of Personality: Theory and Research $\left(2^{\text {nd }} . E d.\right)($ pp.553-575). New York: The Guilford Press.

Christiansen, C. H., Backman, C., Little, B. R., \& Nguyen, A. (1999). Occupations and well-being: A study of personal projects. American Journal of Occupational Therapy, 53, 91-100. 
Costa, P. T., \& McCrea, R. R. (1992). Normal personality assessment in clinical practice: The NEO personality inventory. Psychological Assessment, 4, 513.

Edwards, J. R. (1992). A cybernetic theory of stress, coping, and well-being in organizations. Academy of Management Review, 17(2), 238-274.

Edwards, J. R. (1998) Cybernetic Theory of stress coping and well-being: Review and extension to work and family. In Cooper, C. C. (Ed.), Theories of Organizational Stress (pp.122-152). New York: Oxford Printing Press.

Elliot, A. J., \& Freidman, R. (2007). Approach avoidance: Central characteristics of personal goals. In Little, B. R., Salmela-Aro, K., \& Phillips, S. D. (Eds.), Personal Project Pursuit: Goals Action, and Human Flourishing (pp.97118). Mahwah, New Jersey: Lawrence Erlbaum Associates.

Emmons, R. A. (1986). Personal strivings: An approach to personality and subjective well-being. Journal of Personality and Social Psychology, 51, 1058-1068.

Emmons, R. A., \& King, A. (1988). Conflict among personal strivings: Immediate and long-term implications for psychological and physical well-being. Journal of Personality and Social Psychology, 54(6), 1040-1048.

Ford, M. T., Heinen, B. A., \& Langkamer, K. L. (2007). Work and Family Satisfaction and Conflict: A Meta-Analysis of Cross-Domain Relations. Journal of Applied Psychology, 92(1), 57-80.

Frone, M. R., Russell, M., \& Cooper, M. L. (1997). Relation of work-family conflict to health outcomes: A four-year longitudinal study of employed 
parents. Journal of Occupational and Organizational Psychology, 70, 325335.

Frone, M. R., Yardley, J. K., \& Markel, K. S. (1997). Developing and testing an integrative model of the work-family interface. Journal of Vocational Behavior, 50(2), 145-167.

Greenhaus, J. H., \& Beutell, J. (1985). Sources and conflict between work and family roles. Academy of Management Review, 10(1), 76-88.

Greenberger, E., Steinberg, D., \& Vaux, A. (1981). Adolescents who work: Health and behavioral consequences of job stress. Developmental Psychology, 17(6), 691-703.

Grzywacz, J. G. (2000). Work-family spillover and health during midlife: Is managing conflict everything? American Journal of Health Promotion, 14, 236-243.

Jaros, S. (1997). An assessment of Meyer and Allen's (1991) three component model of organizational commitment and turnover intentions. Journal of Vocational Behavior, 51, 319-337.

Kahn, R. L., Wolfe, D. M., Quinn, R., Snoek, J. D., \& Rosenthal, R. A. (1964). Organizational Stress. New York: Wiley.

Karoly, P., \& Ruehlman, S. (1996). Motivational implications of pain: Chronicity, psychological distress, and work goal construal in a national sample of adults. Health Psychology, 15(5), 383-390. 
Karoly, P., et al. (2005). Perceived self-regulation of exercise goals and interfering goals among regular and irregular exercisers: A life space analysis. Psychology of Sport and Exercise, 6, 427-442.

Kehr, H. M. (2003). Goal conflicts, attainment of new goals, and well-being among managers. Journal of Occupational Health Psychology, 8, 195-208.

Klinger, E. (1977). Meaning and void: Inner experience and the incentives in people's lives. Minneapolis: University of Minnesota Press.

Klein, H. J., Wesson, M. J., Hollenbeck, J. R., \& Alge, B. J. (1999). Goal commitment and the goal-setting process: Conceptual clarification and empirical synthesis. Journal of Applied Psychology, 84(6), 885-896.

Kossek, E. K., \& Ozeki, C. (1999). Bridging the work-family policy and productivity gap: A literature review. Community, Work \& Family, 2, 7-32.

Lazarus, R. S. \& Folkman, S. (1984). Stress appraisal and coping. New York: Springer Publishing Company, Inc.

Little, B. R. (1983). Personal projects: A rationale and method for investigation. Environment and Behavior, 15(3), 273-309.

Little, B. R. (1989). Personal project analysis: Trivial pursuits magnificent obsessions, and the search for coherence. In Buss, D. M. \& Cantor, N. (Eds.), Personality Psychology: Recent Trends and Emerging Directions (pp.15-31). New York: Springer.

Little, B. R. (1999). Personality and motivation: Personal action and conative evolution. In Pervin, L. A., \& John, O. P. (Eds.), Handbook of Personality: 
Theory and Research (2 ${ }^{\text {nd }}$. Ed.) (pp.501-524). New York: The Guilford Press.

Little, B. R. (2007). Prompt and circumstance: The generative contexts of personal projects analysis. In Little, B. R., Salmela-Aro, K., \& Phillips, S. D. (Eds.), Personal Project Pursuit: Goals Action, and Human Flourishing (pp.3-50). Mahwah, New Jersey: Lawrence Erlbaum Associates.

Little, B. R., \& Gee, T. L. (2007). The methodology of personal project analysis: Four modules and a funnel. In Little, B. R., Salmela-Aro, K., \& Phillips, S. D. (Eds.), Personal Project Pursuit: Goals Action, and Human Flourishing (pp.51-96). Mahwah, New Jersey: Lawrence Erlbaum Associates.

Locke, E. A. (1968). Effects of knowledge of results, feedback in relation to standards, and goals on reaction-time performance. American Journal of Psychology, 81(4), 566-574.

Locke, E. A., \& Latham, P. (1990). A theory of goal setting \& task performance. Prentice Hall, Englewood Cliffs, N.J.

Locke, E. A. (1994). The emperor is naked. Applied Psychology: An International Review, 43, 367-370.

Locke, E. A., \& Latham, P. (2002). Building a practically useful theory of goal setting and task motivation: A 35-year odyssey. American Psychologist, 57(9), 705-717.

Maier, G. W., \& Brunstein, J. C. (2001). The role of personal work goals in newcomers' job satisfaction and organizational commitment: A longitudinal analysis. Journal of Applied Psychology, 86, 1032-1042. 
Markel, K. S., \& Frone, R. (1998). Job characteristics, work-school conflict, and school outcomes among adolescents: Testing a structural model. Journal of Applied Psychology, 83(2), 277-287.

McGregor, I., \& Little, B. R. (1998). Personal projects, happiness, and meaning: On doing well and being yourself. Journal of Personality and Social Psychology, 74, 494-512.

McKee, J. M., Alarcon, G., \& Edwards, J. M. (2007). Workplace context and proactive self-regulatory coping as predictors of burnout/boredom. Accepted for poster session at the annual meeting of the Society for Industrial Organizational Psychology, New York, NY.

McKee, J. M., Edwards, J. M., Martin, P. A., Miller, C. E., Hershberger P. J., \& Rudisill, J. R. (2006). Predicting nurse burnout from a self-regulation framework. Manuscript submitted for publication.

McKeeman, D., \& Karoly, P. (1991). Interpersonal and intrapsychic goal-related conflict reported by cigarette smokers, unaided quitters, and relapsers. Addictive Behaviors, 16(6), 543-548.

Maier, G. W., \& Brunstein, J C. (2001). The role of personal work goals in newcomers' job satisfaction and organizational commitment: A longitudinal analysis. Journal of Applied Psychology, 86, 1034-1042.

Mortimer, J. T., Finch, M., Shanahan, M., \& Ryu, S. (1992). Work experience, mental health, and behavioral adjustment in adolescence. Journal of Research on Adolescence, 2(1), 25-57. 
Murphy, K. R., \& Cleveland, J. N. (1995). Understanding performance appraisal: Social organizational, and goal-based perspectives. Sage Publications, Inc., Thousand Oaks, CA.

Netemeyer, R. G., Boles, J. S., \& McMurrian, R. (1996). Development and validation of work-family conflict and family-work conflict scales. Journal of Applied Psychology, 81(4), 400-410.

Nurmi, J., \& Salmela-Aro, K. (2002). Goal construction, reconstruction and depressive symptoms in a life-span context: The transition from school to work. Journal of Personality, 70, 385-420.

Nurmi, J., Salmela-Aro, K., \& Koivisto, P. (2002). Goal importance and related achievement beliefs and emotions during the transition from vocational school to work: Antecedents and consequences. Journal of Vocational Behavior, 60, 241-261.

O'Driscoll, M. P., Ilgen, D. R., \& Hildreth, K. (1992). Time devoted to job and offjob activities, interrole conflict, and affective experiences. Journal of Applied Psychology, 77(3), 272-279.

Perrewé, P. L., Hochwarter, W. A., \& Kiewitz, C. (1999). Value attainment: An explanation for the negative effects of work-family conflict on job and life satisfaction. Journal of Occupational Health Psychology, 4, 318-326.

Powers, W. T. (1973). Feedback: Beyond behaviorism. Science, 179, 351-356.

Riediger, M. (2007). Interference and facilitation among personal goals: Age differences and associations with well-being and behavior. In Little, B. R., Salmela-Aro, K., \& Phillips, S. D. (Eds.), Personal Project Pursuit: Goals 
Action, and Human Flourishing (pp.119-144). Mahwah, New Jersey:

Lawrence Erlbaum Associates.

Salmela-Aro, K., \& Nurmi, J. (1996). Uncertainty and confidence in interpersonal projects: Consequences for social relationships and well-being. Journal of Social and Personal Relationships, 13, 109-122.

Salmela-Aro, K., \& Nurmi, J. (1997a). Personal project appraisals, academic achievement and related satisfaction: A prospective study. European Journal of Psychology of Education, 12, 77-88.

Salmela-Aro, K., \& Nurmi, J.E. (1997b). Positive and negative self-related goals and subjective well-being: A prospective study. Journal of Adult Development, 4, 179-188.

Salmela-Aro, K., \& Nurmi, J. (1997c). Goal contents, well-being, and life context during transition to university: A longitudinal study. International Journal of Behavioral Development, 20, 471-491.

Salmela-Aro, K., \& Nurmi, J. (2004). Employees' motivational orientation and well-being at work. Journal of Organizational Change, 17, 471-489.

Spector, P. E., \& Jex, S. M. (1998). Development of Four Self-Report Measures of Job Stressors and Strain: Interpersonal Conflict at Work Scale, Organizational Constraints Scale, Quantitative Workload Inventory, and Physical Symptoms Inventory. Journal of Occupational Health Psychology, 3, 356-367. 
Wiese, B., \& Freund, A. M. (2005). Goal progress makes one happy, or does it? Longitudinal findings from the work domain. Journal of Occupational and Organizational Psychology, 78, 287-304.

Wiley, D. L. (1987). The relationship between work/nonwork role conflict and jobrelated outcomes: Some unanticipated findings. Journal of Management, $13(3), 467-472$.

Wirtz, P. W., Rohrbeck, C. A., Charner, I., \& Fraser, B. S. (1988). Employment of adolescents while in high school: Employment intensity, interference with schoolwork, and normative approval. Journal of Adolescent Research, 3(1), 97-105.

Wrosch, C., Scheier, S.F., Miller, G.E., Schulz, R., \& Carver, C.S. (2003). Adaptive Self-Regulation of Unattainable Goals: Goal Disengagement, Goal Reengagement, and Subjective Well-Being. Personality and Social Psychology Bulletin, 29, 1494-1508.

Yamamoto, T., Sawada, H., Minami, H., Ishii, S., \& et al, . (1992). Transition from the university to the workplace. Environment and Behavior, 24, 189-205. 